\title{
Application of COSMO-RS and UNIFAC for ionic liquids based gas separation
}

\author{
Liu, Xinyan; Zhou, Teng; Zhang, Xiangping; Zhang, Suojiang; Liang, Xiaodong; Gani, Rafiqul; \\ Kontogeorgis, Georgios M.
}

Published in:

Chemical Engineering Science

Link to article, DOI:

10.1016/j.ces.2018.08.002

Publication date:

2018

Document Version

Peer reviewed version

Link back to DTU Orbit

Citation $(A P A)$ :

Liu, X., Zhou, T., Zhang, X., Zhang, S., Liang, X., Gani, R., \& Kontogeorgis, G. M. (2018). Application of COSMO-RS and UNIFAC for ionic liquids based gas separation. Chemical Engineering Science, 192, 816-828. https://doi.org/10.1016/j.ces.2018.08.002

\section{General rights}

Copyright and moral rights for the publications made accessible in the public portal are retained by the authors and/or other copyright owners and it is a condition of accessing publications that users recognise and abide by the legal requirements associated with these rights.

- Users may download and print one copy of any publication from the public portal for the purpose of private study or research.

- You may not further distribute the material or use it for any profit-making activity or commercial gain

- You may freely distribute the URL identifying the publication in the public portal 


\title{
Application of COSMO-RS and UNIFAC for Ionic Liquids based
}

\section{Gas Separation}

\author{
Xinyan Liu ${ }^{\mathrm{a}, \mathrm{b}}$, Teng Zhou ${ }^{\mathrm{c}}$, Xiangping Zhang ${ }^{\mathrm{b} *}$, Suojiang Zhang ${ }^{\mathrm{b}}$, Xiaodong Liang ${ }^{\mathrm{a}}$, Rafiqul \\ Gani $^{\mathrm{d}}$, Georgios M. Kontogeorgis ${ }^{\mathrm{a}^{*}}$ \\ ${ }^{a}$ Department of Chemical \& Biochemical Engineering, Technical University of Denmark, DK 2800 \\ Kgs. Lyngby, Denmark \\ ${ }^{b}$ Beijing Key Laboratory of Ionic Liquids Clean Process, CAS State Key Laboratory of Green Process \\ and Engineering, Institute of Process Engineering, Chinese Academy of Sciences, Beijing 100190, \\ China \\ ${ }^{c}$ Process Systems Engineering, Max Planck Institute for Dynamics of Complex Technical Systems, \\ Sandtorstr. 1, D-39106 Magdeburg, Germany \\ ${ }^{d}$ PSE for SPEED, Skyttemosen 6, DK-3450 Allerod, Denmark \\ *Corresponding authors \\ Email address: gk@kt.dtu.dk;xpzhang@ipe.ac.cn
}

\begin{abstract}
In recent years, due to their advantages on good stability, non-volatility, tunable viscosity and tailor-made properties, ionic liquids (ILs) have been regarded as novel potential solvents and alternative media for gas separation. However, the various cations and anions representing the ILs, together with limited experimental data, make it challenging to predict gas solubility in ILs and identify the optimal IL for a specific gas separation. In this work, a comprehensive Henry's law constants database is first established for gas-IL which supplements an already established extensive gas solubility database. Because of the insufficient experimental data for both $\mathrm{IL}-\mathrm{C}_{2} \mathrm{H}_{4}$ and $\mathrm{IL}_{-} \mathrm{C}_{2} \mathrm{H}_{6}$ systems, the COSMO-RS model is used after validation to generate additional pseudo-experimental data. Then, together with the sufficient experimental data of $\mathrm{CO}_{2}$-IL and $\mathrm{CH}_{4}$-IL systems, UNIFAC-IL is developed for the prediction of four-component shale gas $\left(\mathrm{CH}_{4}\right.$, $\mathrm{C}_{2} \mathrm{H}_{4}, \mathrm{C}_{2} \mathrm{H}_{6}, \mathrm{CO}_{2}$ ) solubility in ILs. A relatively good agreement between the model predicted and the experimental solubility data is observed. Moreover, the developed UNIFAC-IL model can be used to predict the solubility of gases in new ILs that are not included in parameter fitting due to its group contribution basis. For this reason, the model represents a very useful tool for task-specific design of ionic liquids for gas separations.
\end{abstract}

Keywords: Ionic Liquids (ILs); COSMO-RS; UNIFAC; Gas solubility; Henry’s law constant

\section{Introduction}

Separation and purification technologies are widely used in modern industry and research area, such as gas separation, material production and environmental protection, and they are indispensable units in many industrial production processes. Currently, the commonly used gas separation technologies are energy intensive distillFation, solvent based absorption, flux limited adsorption, and membrane-based operations. Distillation is extensively used for some light hydrocarbon gas separation processes in which the separated gas is recognized as an important raw gas for synthesizing many industrial chemicals. Such distillation processes usually involve columns with large numbers of trays operating at low temperatures and high pressures, which leads to a high energy consumption and negative environmental impact Tula et al., (2017). Thus, solvent based absorption technology is an alternative to overcome these disadvantages. It is widely 
used for separating gas mixtures coming from power or chemical plants containing $\mathrm{CO}_{2}, \mathrm{H}_{2} \mathrm{~S}$ and so on, which need to be removed in order to meet the emission standard of air pollutants. Currently, there are two kinds of solvents for these gases removing. One type is classified as chemical solvents such as monoethanolamine (MEA), methyldiethanolamine (MDEA) or diethanolamine (DEA) Afkhamipour et al., (2014). The other is a physical solvent where solvent-blends like Selexol Kapetaki et al., (2015) or Rectisol Sun et al., (2013) are applied. However, both of these two types of solvents have disadvantages, for example, the chemical solvent may lead to a high vaporization temperature; large solvent loss; high energy consumption for solvent regeneration; while the traditional physical solvents may result in a lower gas recovery because of the low gas capacity. Therefore, developing innovative, energy-saving and "green" solvents for related absorption technologies have received much attention by many researchers.

Recently, ionic liquids (ILs) have been considered as potential substitutes to the chemical solvents as well as the physical ones due to their non-volatility, good stability which can overcome the disadvantages of chemical solvents, and also because of their tailor-made properties such as high solubility and selectivity, which can also avoid the disadvantages of physical ones Cao et al., (2018). Blanchard et al. Blanchard et al., (1999) first reported in 1999 that $\mathrm{CO}_{2}$ is soluble in [bmim $]\left[\mathrm{PF}_{6}\right]$ under $8 \mathrm{MPa}$, attracting more studies on gas solubilities in ILs. Zhang et al. Zhang et al., (2012) reviewed the research progress on $\mathrm{CO}_{2}$ capture with ILs until 2012. The $\mathrm{CO}_{2}$ capture capacities of pure ILs and IL mixtures are summarized and compared. Besides, the optimal design and economic assessment of IL-based process are also discussed. Lei et al. Lei et al., (2014a) studied the capture of gases using ILs, where the solubility data of a series of important gases such as $\mathrm{CO}_{2}, \mathrm{SO}_{2}, \mathrm{CO}, \mathrm{N}_{2}, \mathrm{O}_{2}$ and some light hydrocarbon gases are reviewed over a wide range of temperatures and pressures. It is found that some ILs show very distinct solvation capacities for different gases, indicating a high-potential for their application to the corresponding gas separations. However, because of the numerous possible combinations of anions and cations present in ILs, the current available experimental IL-data is unable to represent them all and it is time-consuming to measure the solubility of each gas in all the ILs of interest. Therefore, in order to find ILs that are suitable as solvents for gas separation, it is important to have the appropriate predictive thermodynamic models which could be used for the design of IL-based gas separation processes. So far, several thermodynamic models have been applied for describing the IL-containing systems, such as equations of state (EoS) Hizaddin et al., (2015; Mota Martinez et al., (2015), empirical models Blath et al., (2011), and group contribution based methods Carlisle et al., (2008) (UNIFAC) Song et al., (2018), quantum chemical calculation based model (COSMO-RS) Fallanza et al., (2013; Han et al., (2018; Lyu et al., (2014; Song et al., (2017; Song et al., (2015; Zhou et al., (2014). Among them, COSMO-RS is a novel model for a priori prediction without relying on any experimental data. It has been widely used for an IL priori screening. As a typical group contribution-based model, UNIFAC model has received much attention for IL design by many researchers. Therefore, in this paper, both two models are taken into consideration for activity coefficient prediction.

The COSMO-RS model is first developed by Klamt et al Klamt et al., (2000). As a predictive method, the COSMO-RS calculation only requires molecular structure information. It has not only been used for predicting solubility of liquid species in ILs Zhou et al., (2012) but also applied for predicting the solubility of gases and screening suitable ILs for different gas mixture separations. Zhang et al. Zhang et al., (2008) use the COSMO-RS model to screen ILs only for $\mathrm{CO}_{2}$ capture. 
However, due to the high deviation between experimental and COSMO-RS predicted properties, it offers only qualitatively correct results Manan et al., (2009). In consideration of this, many authors developed modified COSMO-RS models in which directly linear correction on the Henry's law constant to reduce the systematic error associated with COSMOthermX prediction is proposed Farahipour et al., (2016; Zhao et al., (2015; Zhao et al., (2017). The COSMOthermX is the software based on COSMO-RS model. All of these modified models perform better than the original COSMO-RS model. It is found that the Henry's law constant is predicted through the vapor pressure of gas multiplying the activity coefficient of gas in IL. To validate the COSMOthermX calculation deeply, in this work, the vapor pressure calculated based on the gas energy file from a COSMO-RS approximation model Eckert, (2013) and the activity coefficient value predicted by COSMO-RS are both compared with experiments separately before application. The result shows a large error in vapor pressure prediction. Then linear correction only on the activity coefficient is proposed.

As a result, the simpler group contribution based UNIFAC model is mainly considered for the prediction of gas solubility in ILs. The classical UNIFAC model, with parameters regressed from experimental data, usually shows better predictions of phase equilibrium. The UNIFAC model has recently been extended to IL containing systems by Lei et al. Lei et al., (2012; Lei et al., (2009) for liquid solute-IL systems, and later for $\mathrm{CO}_{2}$-IL systems Lei et al., (2014b). The predicted results agree well with the experiments. Due to the strong electrostatic interactions between cation and anion, they treat the cation and anion as one main group. However, with this approach it is difficult to flexibly tune cations and anions for IL design. In order to expand the IL design space, Roughton et al. Roughton et al., (2012) and Song et al.Song et al., (2018) developed a UNIFAC model to predict liquid-liquid equilibrium of IL systems where ILs are treated as three groups: cation, anion and substituents on the cation. In this work, we employ this strategy to establish a new UNIFAC-IL model to predict vapor-liquid equilibrium for IL-four-gas systems.

In this work, a comprehensive Henry's law constants database is first established for gas-IL which supplements an already established extensive gas solubility database. With the increasing interests on the substituted resources of conventional coal, a model shale gas, mainly containing $\mathrm{CH}_{4}$, and some other gases such as $\mathrm{C}_{2} \mathrm{H}_{4}, \mathrm{C}_{2} \mathrm{H}_{6}, \mathrm{CO}_{2}$, is selected as a case study to highlight the application of the developed predictive thermodynamic models. UNIFAC-IL is developed for the prediction of four-component shale gas $\left(\mathrm{CH}_{4}, \mathrm{C}_{2} \mathrm{H}_{4}, \mathrm{C}_{2} \mathrm{H}_{6}, \mathrm{CO}_{2}\right)$ solubility in ILs. Because of the insufficient experimental data for both $\mathrm{IL}_{-} \mathrm{C}_{2} \mathrm{H}_{4}$ and IL- $\mathrm{C}_{2} \mathrm{H}_{6}$ systems, the COSMO-RS model is considered after validation as a supplementary tool for additional pseudo-experimental data. Detailed calculation sequences for both corrected COSMO-RS model and UNIFAC-IL model are shown in Fig.1. 


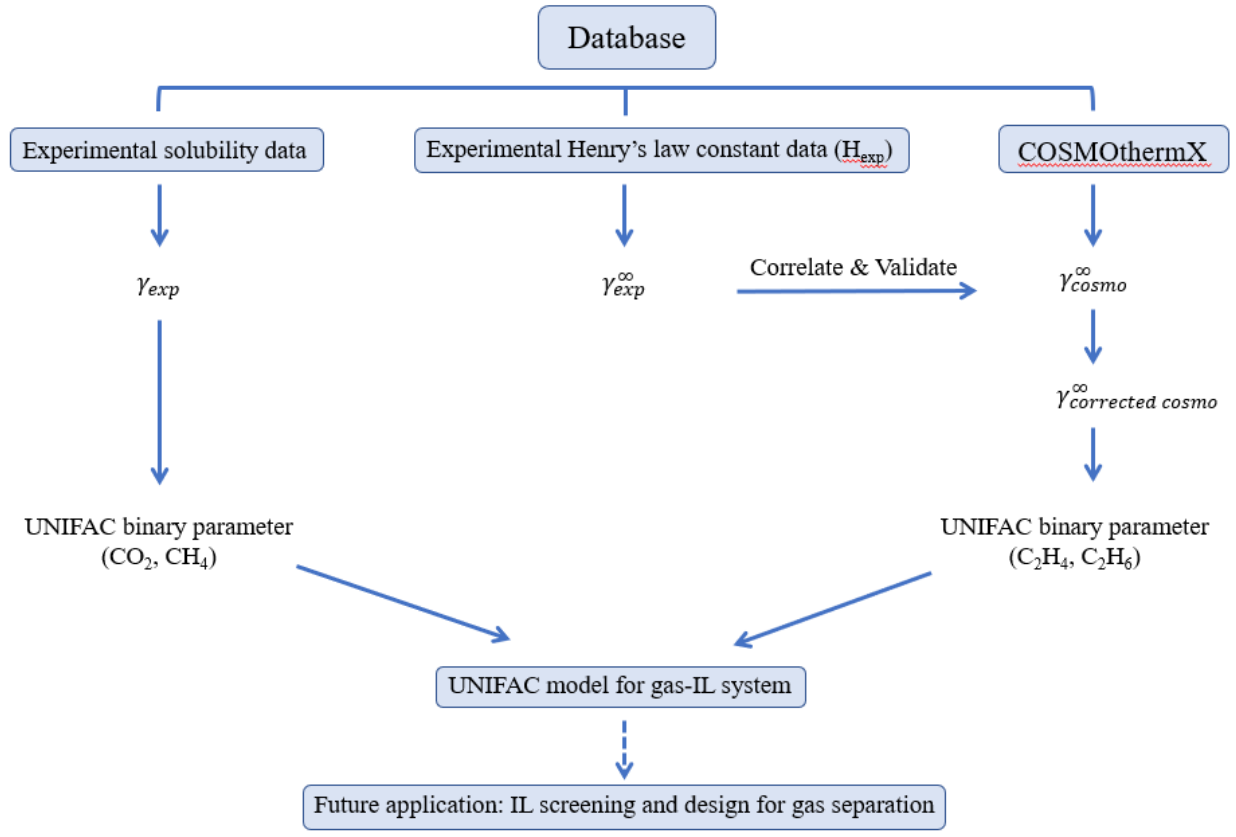

Fig. 1. Calculation sequence for the model development

The paper is organized as follows. The database for experimental solubility and Henry's law constant of gas in IL is first established in section 2.1. Then the COSMO-RS theory and the UNIFAC model are introduced in 2.2 and 2.3 respectively. In section 3, the COSMO-RS based model is developed to predict the activity coefficient of the four gases in ILs. With sufficient experimental and predicted data from the database and COSMO-RS model, the UNIFAC-IL model is further developed. Results of some new group parameter regression and associated discussions for the performance of these two models compared with experiments are presented. Finally in the conclusion (section 4), the application of these two models are discussed and related perspectives has been stated.

\section{Methods and tools}

An IL-database is first established, containing experimental solubility data and Henry's law constants of various gases in different ILs. Based on this database, solubility data of the four gases $\left(\mathrm{CH}_{4}, \mathrm{C}_{2} \mathrm{H}_{4}, \mathrm{C}_{2} \mathrm{H}_{6}, \mathrm{CO}_{2}\right)$ are retrieved for UNIFAC-IL model development. And the activity coefficient data is applied for COSMO-RS model validation and correction.

\subsection{IL-Database}

The prerequisite for developing a thermodynamic model is to build a comprehensive database of measured property data. In this work, our IL-database consists of measured solubility data and Henry's law constants of various gases in a wide range of ILs at different conditions.

The Henry's law constant data, covering 11 different gases, including $\mathrm{CO}_{2}$ and some light hydrocarbon gases, is summarized in Table 1 and details and the corresponding literature sources can be found in Tables S1-S11 of the supporting information.

Table 1 Database information on measured Henry's law constants

\begin{tabular}{|c|c|c|c|}
\hline Gas & Number of ILs & $\begin{array}{c}\text { Number of data } \\
\text { points }\end{array}$ & Temperature range $(\mathrm{K})$ \\
\hline
\end{tabular}




\begin{tabular}{cccc}
\hline $\mathrm{CO}_{2}$ & 36 & 210 & $283-363$ \\
$\mathrm{CH}_{4}$ & 22 & 138 & $283-363$ \\
$\mathrm{C}_{2} \mathrm{H}_{4}$ & 14 & 38 & $283-333$ \\
$\mathrm{C}_{2} \mathrm{H}_{6}$ & 10 & 41 & $283-363$ \\
$\mathrm{C}_{3} \mathrm{H}_{8}$ & 6 & 12 & $303-363$ \\
$\mathrm{C}_{4} \mathrm{H}_{10}$ & 1 & 7 & $303-363$ \\
$\mathrm{~N}_{2} \mathrm{O}$ & 6 & 21 & $293-363$ \\
$\mathrm{~N}_{2}$ & 9 & 46 & $283-363$ \\
$\mathrm{H}_{2}$ & 4 & 28 & $278-343$ \\
$\mathrm{O}_{2}$ & 3 & 19 & $283-343$ \\
$\mathrm{CO}$ & 1 & 9 & $283-343$ \\
\hline $\mathrm{C}_{2} \mathrm{H}_{4}$ & Predicted from the corrected COSMO-RS (Eq. 1,17-19) \\
$\mathrm{C}_{2} \mathrm{H}_{6}$ & 30 & 300 & $288-333$ \\
\hline
\end{tabular}

In this work, we mainly focus on the first four gases (see Table 1), which are the main components of shale gas. These experimental Henry's law constants are compared with those obtained with the COSMO-RS model and make, where necessary, corrections to get a more consistently correct data. As a result, the accuracy of these collected experimental data is very important. Therefore, in the literature survey, to obtain the reliable data to be applied, on the one side, we make sure that the reported data of Henry's law constants of each gas in ILs at various temperatures are measured under the same method, on the other hand, we choose the data to be consistent under same conditions in different sources. In details, we have observed that more data are available for IL- $\mathrm{CO}_{2}$ systems and the same binary systems have been measured by several authors. The more reliable data points with reported small deviations are retained in the database; otherwise the data is removed. For instance, the Henry's law constant of $\mathrm{CO}_{2}$ in [bmim] $\left[\mathrm{Tf}_{2} \mathrm{~N}\right]$ under $298 \mathrm{~K}$ is reported by several authors. The values in the range 32.8 to 43 are retained Lee et al., (2015; Muldoon et al., (2007; Sistla et al., (2011) while the value of 16.2 Pereira et al., (2013), which deviates a lot from all other values is considered to be an outlier and is thus deleted. Then based on the activity coefficient predicted by the corrected COSMO-RS model and experimental vapor pressure data additional Henry's law constant pseudo-experimental data of $\mathrm{C}_{2} \mathrm{H}_{4}$ and $\mathrm{C}_{2} \mathrm{H}_{6}$ in 30 ILs under various temperatures is calculated and added to the database.

Besides the Henry's law constant database, a solubility database covering 16 gases is also developed based on Lei's database Lei et al., (2014a). From literature review, some more data points of solubility property are added. Here, we only focus on the ILs which have physical absorption on the gas. The related information is given in Table 2, while detailed values and the corresponding literature sources can be found in the Supporting Information (Table S12-S27).

Table 2 Database information on measured solubility data

\begin{tabular}{cccc}
\hline Gas & Number of ILs & $\begin{array}{c}\text { Number of data } \\
\text { points }\end{array}$ & Temperature range (K) \\
\hline $\mathrm{CO}_{2}$ & 103 & 4742 & $271-453$ \\
$\mathrm{CH}_{4}$ & $8+2$ & $313+42$ & $283-453$ \\
$\mathrm{C}_{2} \mathrm{H}_{4}$ & 3 & 254 & $283-333$ \\
\hline
\end{tabular}




\begin{tabular}{cccc}
\hline $\mathrm{C}_{2} \mathrm{H}_{6}$ & $13+1$ & $474+29$ & $283-368$ \\
$\mathrm{C}_{3} \mathrm{H}_{8}$ & $2+1$ & $33+50$ & $280-380$ \\
$\mathrm{C}_{4} \mathrm{H}_{10}$ & 1 & 16 & $280-340$ \\
$\mathrm{~N}_{2} \mathrm{O}$ & $11+1$ & $513+31$ & $283-373$ \\
$\mathrm{~N}_{2}$ & $8+1$ & $118+29$ & $283-343$ \\
$\mathrm{H}_{2}$ & 12 & 265 & $278-453$ \\
$\mathrm{O}_{2}$ & 12 & 582 & $283-413$ \\
$\mathrm{CO}$ & 5 & 101 & $283-413$ \\
$\mathrm{H}_{2} \mathrm{~S}$ & 15 & 722 & $298-403$ \\
$\mathrm{NH}_{3}$ & 7 & 225 & $282-355$ \\
$\mathrm{SO}_{2}$ & 16 & 301 & $282-413$ \\
$\mathrm{C}_{3} \mathrm{H}_{6}$ & 1 & 16 & $280-340$ \\
$\mathrm{C}_{4} \mathrm{H}_{8}$ & 1 & 16 & $280-340$ \\
\hline
\end{tabular}

Note: the number after "+" denotes our collected data.

\subsection{COSMO-RS based model for Henry's law constant}

COSMO-RS combines an electrostatic theory of locally interacting molecular surface descriptors (which are available from quantum chemical (QC) calculations) with a statistical thermodynamics methodology. It is regarded as a valuable tool for predicting activity coefficients and thermo-physical properties Klamt et al., (2000).

The Henry's law constant is determined through Eq.1

$$
H_{i}^{s}=\gamma_{i}^{s, \infty} p_{i}^{s}
$$

where $p_{i}^{S}$ is the vapor pressure. $\gamma_{i}^{s, \infty}$ is the infinite dilute activity coefficient of compound $i$. In COSMO-RS model, the activity coefficient is calculated from the chemical potential $\mu_{i}^{p}$ of the pure compounds $i$ and the chemical potential $\mu_{i}^{j}$ at infinite dilution in compound $j$, as seen in Eq. 2 .

$$
\ln \left(\gamma_{i}\right)=\left(\mu_{i}^{j}-\mu_{i}^{p}\right) / R T
$$

where $\mu_{i}^{j}$ is the chemical potential of compound $i$ in the liquid phase (compound $j$ or mixture system $s), \mu_{i}^{p}$ is the chemical potential of pure compound $i$ at the same temperature. The chemical potential of compound $i$ in system $S$ is readily available from the integration of $\mu_{S}(\sigma)$ over the surface of the compound, as given by Eq.3.

$$
\mu_{i}^{s}=\mu_{i}^{c, s}+\int p_{i}(\sigma) \mu_{s}(\sigma) d \sigma
$$

where $p_{i}(\sigma)$ is called " $\sigma$-profiles", the probability distribution of $\sigma$ for all compounds $i$, which can describe the composition of the surface segment ensemble with respect to the interactions. The $\sigma$-profiles is defined by Eq. 4 .

$$
p_{i}(\sigma)=\frac{n_{i}(\sigma)}{n_{i}}=\frac{A_{i}(\sigma)}{A_{i}}
$$

where $n_{i}(\sigma)$ is the number of segments with charge density $\sigma$ that have a surface area $A_{i}(\sigma)$, and $n_{i}$ is the total number of segments in a single molecule with a total surface area $A_{i}$. All of these surface area, charge density information is calculated through quantum chemical calculation which can be obtained directly from COSMO output file in COSMOthermX software.

In the COSMO-RS theory, the most important molecular interactions such as electrostatics $\left(E_{\text {misfit }}\right)$ and hydrogen bonding $\left(E_{H B}\right)$ are taken into account as functions of the polarization 
charges of two interacting surface segments $\sigma$ and $\sigma^{\prime}$. The less specific van der Waals $\left(E_{v d W}\right)$ interactions are described in a slightly more approximate way. The above-mentioned interactions are given by Eqs. 5-7 as follows:

$$
\begin{gathered}
E_{\text {misfit }}\left(\sigma, \sigma^{\prime}\right)=a_{e f f} e_{\text {misfit }}\left(\sigma, \sigma^{\prime}\right)=a_{e f f} \frac{\alpha^{\prime}}{2}\left(\sigma+\sigma^{\prime}\right) \\
E_{H B}\left(\sigma, \sigma^{\prime}\right)=a_{e f f} c_{H B} \min \left\{0, \min \left(0 ; \sigma_{\text {donor }}+\sigma_{H B}\right) \max \left(0 ; \sigma_{\text {acceptor }}-\sigma_{H B}\right)\right\} \\
E_{v d W}\left(\sigma, \sigma^{\prime}\right)=a_{e f f}\left(\tau_{v d W}+\tau_{v d W}^{\prime}\right)
\end{gathered}
$$

where $a_{e f f}$ is the contact surface area; $\alpha^{\prime}$ is an adjustable parameter (the energy factor); $\sigma$ and $\sigma^{\prime}$ are net screening charge densities (SCDs). $c_{H B}$ and $\sigma_{H B}$ are adjustable parameters of the HB interaction energy. $\tau_{v d W}$ and $\tau_{v d W}^{\prime}$ are element-specific parameters.

As a result, the chemical potential of a surface segment with $\operatorname{SCD} \sigma$, i.e., $\sigma$-potential $\mu_{s}(\sigma)$, is given by Eq. 8 .

$$
\mu_{s}(\sigma)=-\frac{\mathrm{RT}}{a_{e f f}} \times \ln \left[\int p_{s}\left(\sigma^{\prime}\right) \exp \left\{\frac{a_{e f f}}{R T}\left(\mu_{s}\left(\sigma^{\prime}\right)-E_{\text {misfit }}\left(\sigma, \sigma^{\prime}\right)-E_{H B}\left(\sigma, \sigma^{\prime}\right)\right)\right\} d \sigma^{\prime}\right]
$$

In this study, the COSMOthermX (version C3.0, release 14.01)Eckert, (2013), where the COSMO-RS theory is implemented, is applied for the prediction of four gas solubilities $\left(\mathrm{CH}_{4}\right.$, $\mathrm{C}_{2} \mathrm{H}_{4}, \mathrm{C}_{2} \mathrm{H}_{6}, \mathrm{CO}_{2}$ ) in ILs. The $\sigma$-profiles of calculated ILs represented by different cations and anions are retrieved from the IL Thermo Database Eckert, (2013). And the $\sigma$-profiles of $\mathrm{CH}_{4}, \mathrm{C}_{2} \mathrm{H}_{6}$ and $\mathrm{CO}_{2}$ are taken from software database. For $\mathrm{C}_{2} \mathrm{H}_{4}$, the profiles are optimized by the Gaussian 09 B.01 software Frisch et al., (2010) at the B3LYP/6-31+ $+\mathrm{G}^{* *}$ theoretical level in the ideal gas phase using the quantum-chemical calculation option. Frequency analysis is performed to ensure that no imaginary frequency exists and to confirm the minimization of energy. The COSMO files of $\mathrm{C}_{2} \mathrm{H}_{4}$ are calculated by the Gaussian 03 Frisch et al., (2004) package using the BVP86/TZVP/DGA1 level of theory. Then, the COSMO files of these gases are used as input in the COSMOthermX code to perform further calculations.

In COSMOthermX, the activity coefficient is directly predicted by Eq. 2, and related chemical potentials are calculated based on Eq. 3-8. The Henry's law constant calculation is based on Eq. 1 where the vapor pressure of gas can be estimated either by a COSMO-RS approximation model Eckert, (2013) or empirical correlation models (such as the Wagner, DIPPR, and Antoine equations). By default, the software uses the first method to estimate vapor pressures. In this work, the DIPPR Lee et al., (2015) equation (Eq.9) is applied as a candidate for the prediction of the Henry's law constant of the four gases $\left(\mathrm{CO}_{2}, \mathrm{CH}_{4}, \mathrm{C}_{2} \mathrm{H}_{4}, \mathrm{C}_{2} \mathrm{H}_{6}\right)$ in ILs and corresponding measured data is retrieved from the Henry's law constant database for the comparison.

$$
P_{i}^{S}(P a)=\exp \left[A_{i}+\frac{B_{i}}{T}+C_{i} \ln T+D_{i} T^{E_{i}}\right]
$$

$A_{i}, B_{i}, C_{i}, D_{i}$, and $E_{i}$ are compound-specific parameters, the values of which can be found from the DIPPR database "https://dippraiche.org/SampleDb," ().

\subsection{UNIFAC-IL model}

The original UNIFAC model Fredenslund et al., (1975) (Eq.A1-A13 in the Appendix) is first developed for the prediction of activity coefficients in liquid mixtures. It is broadly considered to be a predictive thermodynamic model based on the concept of group contribution. Due to this 
predictive character, the model can be applied for solvent screening on many purposes such as the separation of gas mixtures and liquid-liquid extractionLei et al., (2009; Song et al., (2018).

In order to apply the UNIFAC model into IL-containing systems, the IL molecule must first be divided into groups. Three approaches which can be used for this purpose are the following:

1) The IL molecule is divided into one cation and one anion group Santiago et al., (2011; Santiago et al., (2010). For instance, $[\mathrm{BMIM}]\left[\mathrm{BF}_{4}\right]$ can be divided into $[\mathrm{BMIM}]^{+}$and $\left[\mathrm{BF}_{4}\right]^{-}$. This method could not reflect the influence of various substitutes on cation or anion.

2) The IL molecule is divided into several groups including all the substituent groups, but the skeletons of cation and anion are treated as one electrically neutral group so that the additional Debye-Hückel term relating to long-range electrostatic contributions can be neglected Chávezislas et al., (2014; Lei et al., (2014b). In this case, [BMIM] $\left[\mathrm{BF}_{4}\right]$ can be expressed by two main groups, $\mathrm{CH}_{2}$ and $[\mathrm{MIM}]\left[\mathrm{BF}_{4}\right]$. This approach is widely applied not only in UNIFAC developments, but also for some GC-EoS models Bermejo et al., (2009; Breure et al., (2007; Mota Martinez et al., (2015).

3) Similar to method 2, the IL is divided into several groups including alkyl chains, but the skeletons of cation and anion are divided into two groups: the cation core and anion. For the same example, $\mathrm{CH}_{2},[\mathrm{MIM}]^{+}$, and $\left[\mathrm{BF}_{4}\right]^{-}$are identified using this method. Due to the strong interaction and weak dissociation of ion pairs, the interaction parameters between the cation core and anion are assumed to be zero Roughton et al., (2012; Song et al., (2018). The third approach allows for the optimal selection of cation-anion combinations, which largely expands the IL design space. It is due to this reason that we have chosen the third approach in this work.

In the UNIFAC-IL model, the group parameters for volume $R_{k}$ and surface area $Q_{k}$ were determined using the following procedures:

1). The rules of Bondi can be used to estimate $R_{k}$ and $Q_{k}$ Bondi, (1964) (Eq.10-11).

$$
R_{k}=\frac{V_{k}}{15.17} \quad Q_{K}=\frac{A_{k}}{2.5 \times 10^{9}}
$$

2). For groups that have not been defined by the rules of Bondi, values from similar UNIFAC groups were used. For example, the volume and surface area parameters for a di-substituted pyridine group were assumed to be equal to those of a di-substituted pyridinium group Roughton et al., (2012).

3). Otherwise for some groups, values were obtained in literature sources using correlations to molecular volume or molecular simulation to determine volume and surface area parameters Lei et al., (2014b; Lei et al., (2009; Song et al., (2018), as seen in Eq.(12-13).

$$
R_{k}=\frac{V_{k} \times N_{A}}{V_{V W}} \quad Q_{K}=\frac{A_{k} \times N_{A}}{A_{V W}}
$$

where $V_{k}$ and $A_{k}$ are van der Waals group volumes and surface areas of group $k$, respectively. $V_{V W}$ $\left(15.17 \mathrm{~cm}^{3} / \mathrm{mol}\right)$ and $A_{V W}\left(2.5 * 10^{9} \mathrm{~cm}^{2} / \mathrm{mol}\right)$ are standard segment volume and surface area as suggested by Bondi (correspond to the $\mathrm{CH}_{2}$ group in polyethylene), respectively; and $N_{A}$ is the Avogadro's number $\left(6.023 * 10^{23} \mathrm{~mol}^{-1}\right)$. All the final values of $R_{k}$ and $Q_{k}$ are presented in Table 4.

In this case, for $\mathrm{CO}_{2}$ and $\mathrm{CH}_{4}$, we use the corresponding gas solubility data reported in the established database to calculate the experimental activity coefficients in ILs using (Eq. 14). And for $\mathrm{C}_{2} \mathrm{H}_{4}$ and $\mathrm{C}_{2} \mathrm{H}_{6}$, because of the insufficient experimental data and the good predictive performance for IL- $\mathrm{C}_{2} \mathrm{H}_{4}$ and IL- $\mathrm{C}_{2} \mathrm{H}_{6}$ systems, we use the predicted activity coefficients data 
from the corrected COSMO-RS model and calculate the solubility under pressure of 1 bar to correlate the related parameters.

$$
\gamma_{i, \exp }=\frac{P y_{i}}{P_{i}^{S} x_{i}}
$$

where $P$ is the total pressure of the system, $y_{i}$ and $x_{i}$ are the mole fraction of gas $i$ in vapor phase and in liquid phase respectively. $P_{i}^{S}$ is the saturated vapor pressure of gas $i$, calculated from DIPPR (Eq.9) in this work.

The interaction parameters $\left(a_{m n}\right.$ and $\left.a_{n m}\right)$ between some common UNIFAC groups which have been reported, for example $\mathrm{CH}_{2}-\mathrm{CO}_{2}, \mathrm{CH}_{2}-\mathrm{CH}_{4}, \mathrm{CH}_{2}-\mathrm{C}_{2} \mathrm{H}_{4}$ and $\mathrm{CH}_{2}-\mathrm{CH}_{2} \mathrm{O}$. Their values were kept the same as those in the literatures Nocon et al., (1983; Skjoldjorgensen et al., (1979). The other group interaction parameters were considered as unknown parameters, which were regressed by minimizing the objective function, shown as Eq. (15) where $\gamma_{i \text {,cal }}$ indicates the activity coefficients calculated from UNIFAC and $\gamma_{i, \exp }$ denotes the experimental values obtained from Eq. (14). One of the ICAS toolboxes (MoT) Morales-Rodríguez et al., (2008) has been applied to perform this regression. The predicted results are compared with experimental data using the average absolute relative deviation (AARD) given in Eq.(16).

$$
\begin{gathered}
O b j=\sum_{i=1}^{N P}\left(\frac{\gamma_{i, \exp }-\gamma_{i, \text { cal }}}{\gamma_{i, \exp }}\right)^{2} \\
A A R D=\frac{1}{N P} \sum_{i=1}^{N P} \frac{\left|\gamma_{i, \exp }-\gamma_{i, \text { cal }}\right|}{\gamma_{i, \exp }} \times 100 \%
\end{gathered}
$$

Where $N P$ is the total number of data points.

\section{Results and discussion}

\subsection{COSMO-RS model verification and correction}

Before COSMO-RS model is applied to generate the additional pseudo-experimental data, it is necessary to validate and evaluate its deviation with experiments. As mentioned in the introduction, only the four-component shale gas $\left(\mathrm{CH}_{4}, \mathrm{C}_{2} \mathrm{H}_{4}, \mathrm{C}_{2} \mathrm{H}_{6}, \mathrm{CO}_{2}\right)$ is taken into consideration in this work.

As described in section 2.2, the vapor pressure of corresponding gas should be estimated to calculate the Henry's law constant. In order to find the most accurate method, both the COSMO-RS approximation model and DIPPR (Eq.9) are compared with the experimental data, as seen in Fig. 2. The results indicate that the empirical DIPPR equation performs much better for prediction of vapor pressures. Therefore, in this work, we first calculate the experimental activity coefficients from the experimental Henry's law constants and the gas vapor pressures obtained from the DIPPR equation. These activity coefficients are then used to validate and correct the COSMO-RS predictions. 


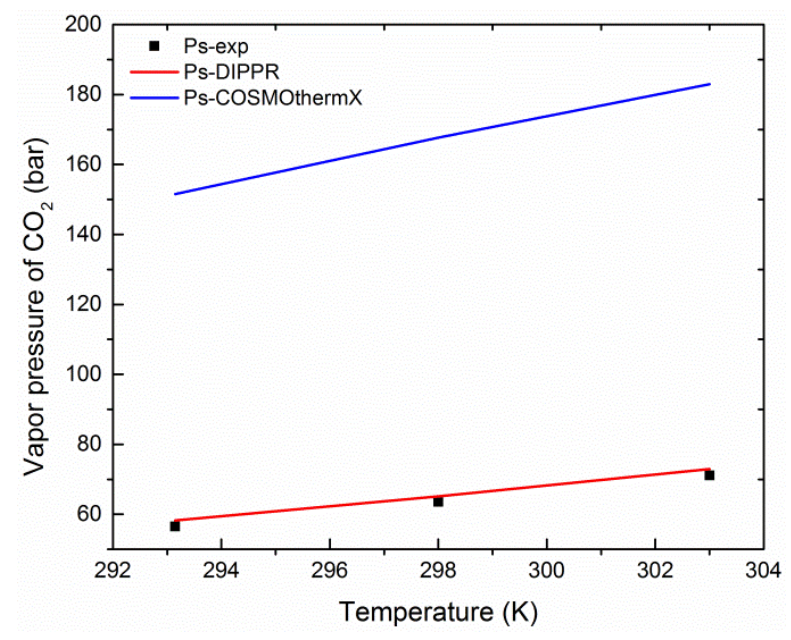

Fig. 2. Comparison of the estimated vapor pressure with the experimental value (corresponding DIPPR equation (Eq.9) coefficients of $\mathrm{CO}_{2}, \mathrm{CH}_{4}, \mathrm{C}_{2} \mathrm{H}_{4}$ and $\mathrm{C}_{2} \mathrm{H}_{6}$ are shown in Table S28 of Supporting information.)

Comparisons between the experimental and COSMO-RS calculated activity coefficients for the four shale gas components $\left(\mathrm{CO}_{2}, \mathrm{CH}_{4}, \mathrm{C}_{2} \mathrm{H}_{4}, \mathrm{C}_{2} \mathrm{H}_{6}\right)$ are performed. As shown in Fig. 3, systematic deviations could be identified, which although from one side it is unfortunate, from the other side it indicates that it is possible to develop systematic corrections to the COSMO-RS model for the prediction of activity coefficients of shale gas components in ILs. Following this idea, we have proposed a temperature-dependent correction model, summarized in equations 17-19 (Table 3), for the light hydrocarbon gases $\left(\mathrm{CH}_{4}, \mathrm{C}_{2} \mathrm{H}_{4}\right.$ and $\left.\mathrm{C}_{2} \mathrm{H}_{6}\right)$.

For $\mathrm{CO}_{2}$, as seen in Fig. 3, the predicted activity coefficients usually underestimate the experimental values. While the experimental value ranges from 0.02 to 2.0 , the predicted results vary in a much smaller scale (from 0.1 to 0.6 ). Therefore, it is difficult to find one universal model to correct the COSMO-RS predicted values, as for the light hydrocarbon gases.

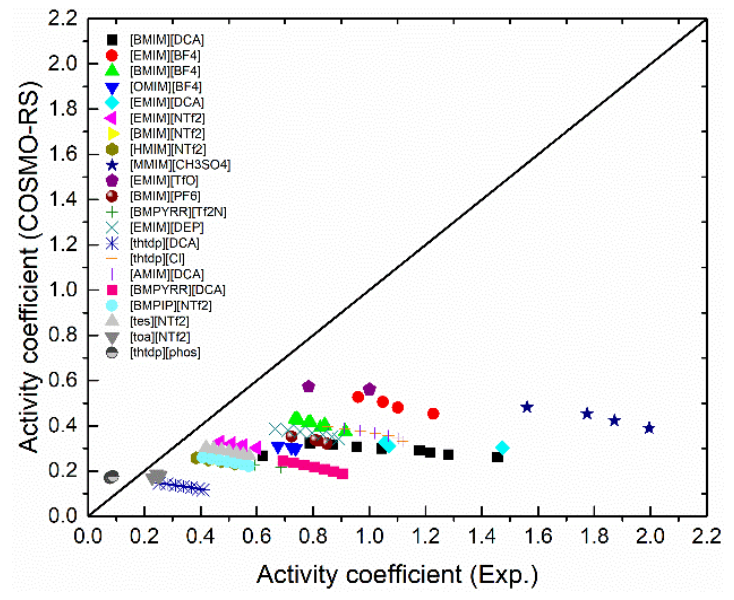

(a)

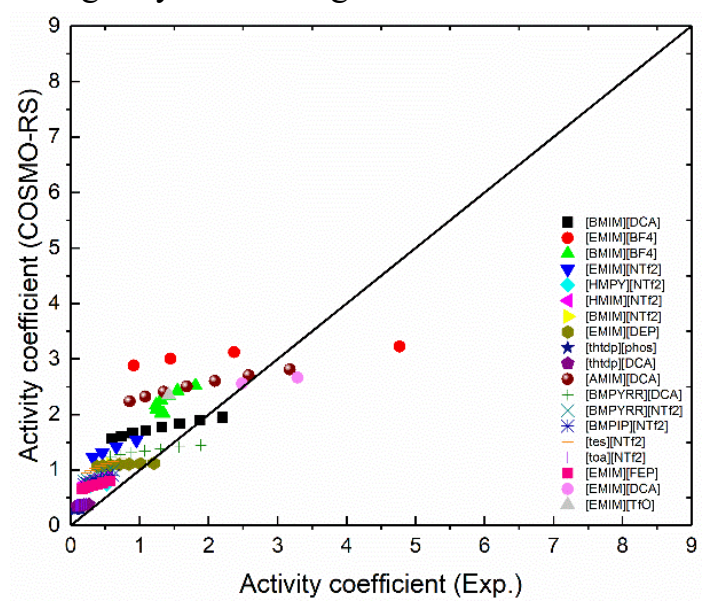

(b) 


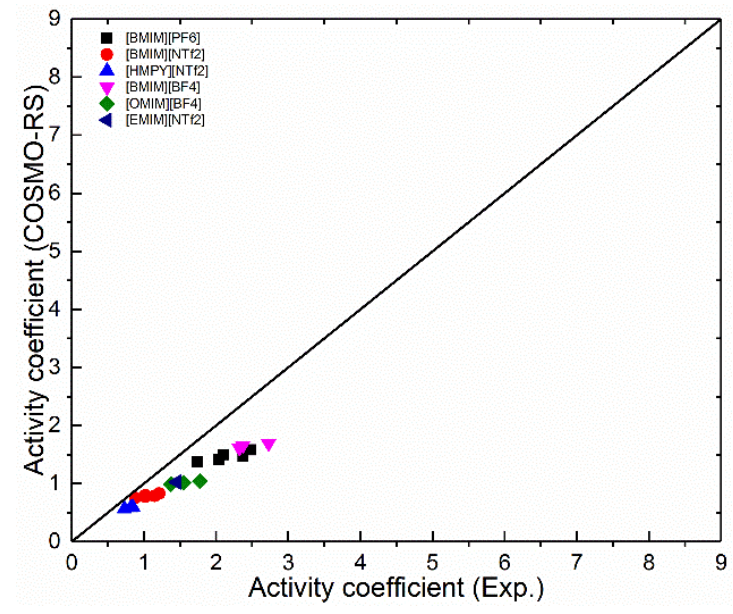

(c)

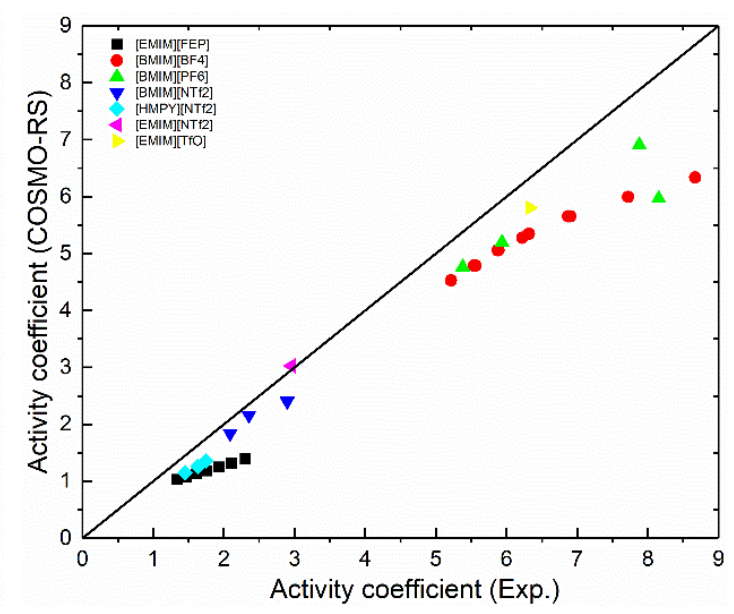

(d)

Fig. 3. Experimental $\gamma_{\text {exp }}^{\infty}$ versus COSMO-RS predicted infinite dilution activity coefficients $\gamma_{\text {cosmo }}^{\infty}$; a) $\mathrm{CO}_{2}$, b) $\mathrm{CH}_{4}$, c) $\mathrm{C}_{2} \mathrm{H}_{4}$, d) $\mathrm{C}_{2} \mathrm{H}_{6}$

As in Table 3, the corrected COSMO-RS models include two parameters, one is the temperature, the other is the activity coefficient from COSMO-RS which can be calculated directly from COSMOthermX software after the $\sigma$-profiles of the IL (in cation and anion, respectively) and gas have been retrieved from the IL Thermo database Eckert, (2013). The related calculation theory has been stated in section 2.2. Then the corrected activity coefficients of each gas in specific IL under various temperatures are calculated.

The accuracy of these models is shown in Fig. 4 and their relative deviations are reported in Table 3 together with the deviations from the original COSMO-RS predictions. Detailed information of the data points' value can be found in Table S29 of the Supporting information. It can be seen that the predicted values from these models are in much better agreement with the experimental data except for $\mathrm{CH}_{4}$ (for which the deviation of about $50 \%$, even after the correction, is still quite large). In both $\mathrm{C}_{2} \mathrm{H}_{4}-\mathrm{IL}$ and $\mathrm{C}_{2} \mathrm{H}_{6}$-IL systems, as a validation for the corrected COSMO-RS model, the experimental activity coefficient data in two ILs is retrieved and calculated for extrapolated validation (seen the test set in Fig.4). The results are turned out to be consistent with experiments. Therefore, pseudo experimental data are generated only for the $\mathrm{C}_{2} \mathrm{H}_{4}-\mathrm{IL}$ and $\mathrm{C}_{2} \mathrm{H}_{6}-\mathrm{IL}$ systems. 
Table 3 Corrected COSMO-RS model for the infinite dilution activity coefficient of three light hydrocarbon gases $\left(\mathrm{CH}_{4}, \mathrm{C}_{2} \mathrm{H}_{4}, \mathrm{C}_{2} \mathrm{H}_{6}\right)$ in ILs

\begin{tabular}{ccccc}
\hline \multirow{2}{*}{ Gas } & Corrected model, T in K & \multicolumn{2}{c}{ AARD with experimental $\gamma^{\infty}$} \\
\cline { 3 - 4 } $\mathrm{CH}_{4}$ & $\gamma_{\text {cor }}^{\infty}=0.771 \gamma_{\cos m o}^{\infty}+2.687-0.0087 T$ & Eq.(17) & $123.4 \%$ & $50.6 \%$ \\
$\mathrm{C}_{2} \mathrm{H}_{4}$ & $\gamma_{\text {cor }}^{\infty}=1.582 \gamma_{\cos m o}^{\infty}+1.268-0.00466 T$ & Eq.(18) & $29.5 \%$ & $6.3 \%$ \\
$\mathrm{C}_{2} \mathrm{H}_{6}$ & $\gamma_{c o r}^{\infty}=1.149 \gamma_{\cos m o}^{\infty}+2.410-0.006699 T$ & Eq.(19) & $19.5 \%$ & $8.9 \%$ \\
\hline
\end{tabular}

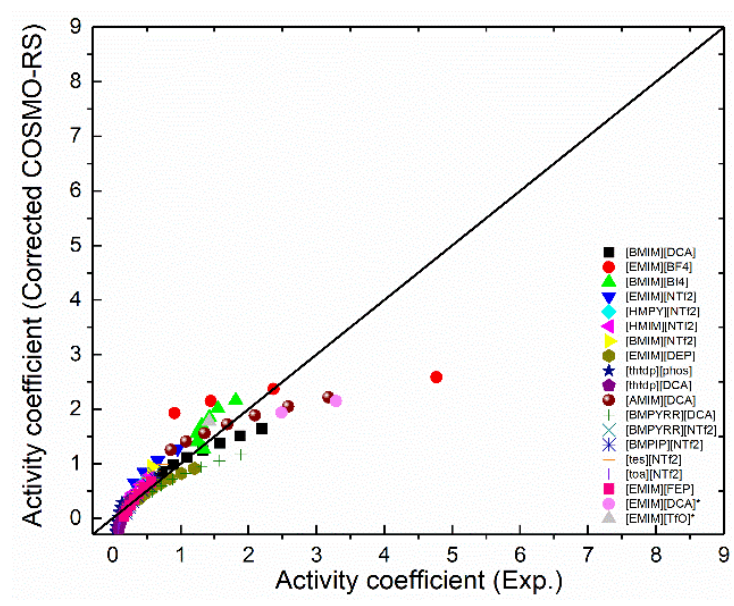

(a)

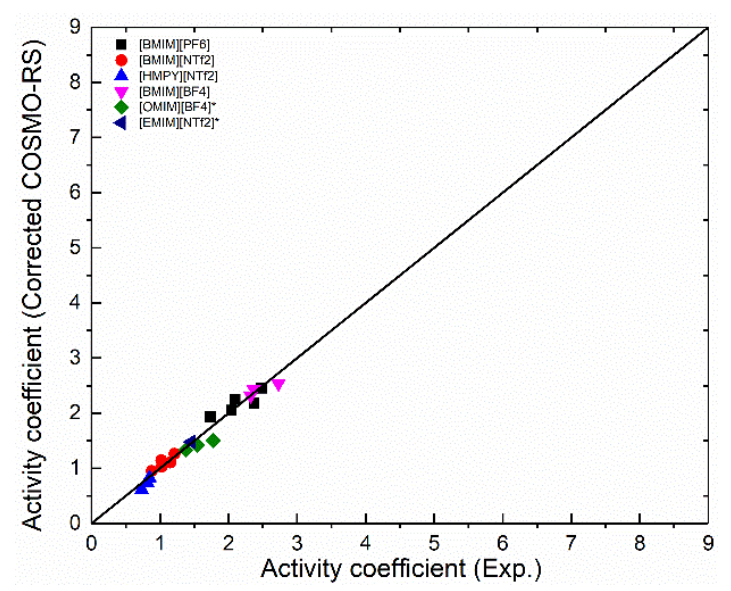

(b)

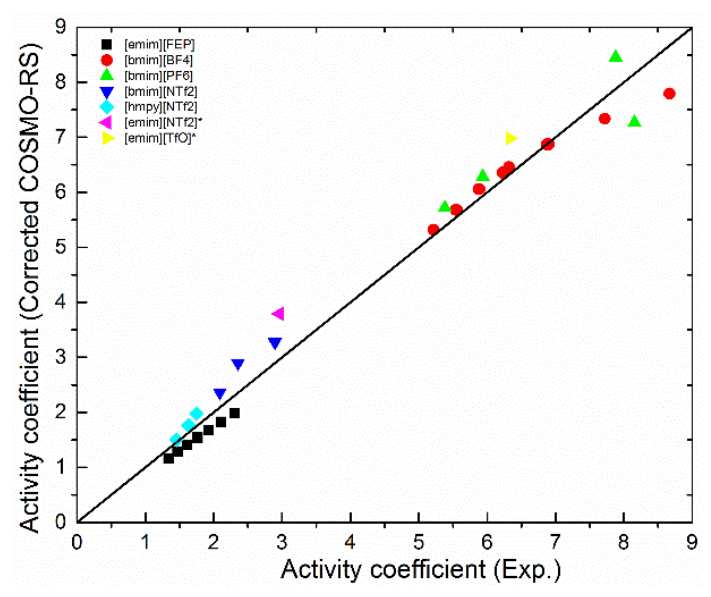

(c)

Fig. 4. Experimental $\gamma_{\text {exp }}^{\infty}$ versus corrected COSMO-RS calculated infinite dilution activity coefficients $\gamma_{\text {cor }}^{\infty}$; a) $\mathrm{CH}_{4}$, b) $\mathrm{C}_{2} \mathrm{H}_{4}$, c) $\mathrm{C}_{2} \mathrm{H}_{6}$

*This symbol corresponds to the test set ILs

In summary, COSMO-RS is a predictive model which is a positive feature but the performance is not always satisfactory for many IL-gas systems. The activity coefficient of gas in ILs, especially for $\mathrm{C}_{2} \mathrm{H}_{4}$ and $\mathrm{C}_{2} \mathrm{H}_{6}$, can be better estimated from the corrected COSMO-RS models which are developed based on experimental observations. Thus, total 600 data points of activity 
coefficient among 60 IL-gas systems are added to the database. The ILs include all combinations of 3 kinds of cation ([EMIM], [BMIM], [HMIM]) with 9 kinds of common anion ([BF 4 , $\left[\mathrm{PF}_{6}\right]$, $\left[\mathrm{Tf}_{2} \mathrm{~N}\right],\left[\mathrm{MeSO}_{4}\right],[\mathrm{TfO}],[\mathrm{DCA}],[\mathrm{SCN}],[\mathrm{DMP}],[\mathrm{eFAP}]$ ) and another 3 ILs ([EMPY] $\left[\mathrm{Tf}_{2} \mathrm{~N}\right]$, [BMPY][Tf $2 \mathrm{~N}]$, [HMPY] $\left.\left[\mathrm{Tf}_{2} \mathrm{~N}\right]\right)$, totally $30 \mathrm{ILs}$ with 2 gases $\left(\mathrm{C}_{2} \mathrm{H}_{4}, \mathrm{C}_{2} \mathrm{H}_{6}\right)$ systems. These added data can be applied for further UNIFAC-IL model development. Fortunately, even though for $\mathrm{CO}_{2}$ and $\mathrm{CH}_{4}$, those semi-predicted values result in large errors from experiments, there is sufficient experimental solubility data in the database. As a result, for $\mathrm{IL}_{-} \mathrm{CO}_{2}$ and $\mathrm{IL}_{-} \mathrm{CH}_{4}$ systems, the UNIFAC-IL model is developed only based on these experimental data.

\subsection{UNIFAC-IL model development}

On the basis of sufficient experimental data and also the validated predicted values on activity coefficient of $\mathrm{C}_{2} \mathrm{H}_{4}$ and $\mathrm{C}_{2} \mathrm{H}_{6}$ in 30 ILs in the database, a UNIFAC-IL model among the four gases $\left(\mathrm{CO}_{2}, \mathrm{CH}_{4}, \mathrm{C}_{2} \mathrm{H}_{4}, \mathrm{C}_{2} \mathrm{H}_{6}\right)$ is developed for improved predictions and also for IL design based on the group contribution principle. As a result, 19 main groups are identified. The group volume and surface area parameters are directly taken from literatures Dahl et al., (1991; Fredenslund et al., (1975; Lei et al., (2009; Nocon et al., (1983; Roughton et al., (2012; Song et al., (2018), and they are presented in Table 4. Based on the experimental solubility database, 37 pairs

of group interaction parameters $a_{m n}$ are fitted for $23 \mathrm{IL}-\mathrm{CO}_{2}$ and $8 \mathrm{IL}-\mathrm{CH}_{4}$ systems. And on the basis of predicted data in the database, another 23 pairs of group interaction parameters are fitted for $30 \mathrm{IL}-\mathrm{C}_{2} \mathrm{H}_{4}$ and $30 \mathrm{IL}-\mathrm{C}_{2} \mathrm{H}_{6}$ systems. Then same 600 data points as in the COSMO-RS model for $\mathrm{IL}_{-} \mathrm{C}_{2} \mathrm{H}_{4}$ and IL- $\mathrm{C}_{2} \mathrm{H}_{6}$ systems are calculated and also compared with experiments and values from corrected COSMO-RS model.

The optimization procedure is performed in a sequential fashion in order to decrease the number of adjustable parameters in each regression. Detailed order of optimization and the corresponding AARD can be found in Table 5. As indicated, during the first regression process, the parameters for groups $\mathrm{CO}_{2},[\mathrm{IM}]^{+}$, and $\left[\mathrm{PF}_{6}\right]^{-}$are regressed using experimental data. The parameters between $\mathrm{CO}_{2}$ and $[\mathrm{IM}]^{+}$are then fixed when regressing the parameters for other anions. The same procedure has been followed for the IL- $\mathrm{CH}_{4}, \mathrm{IL}_{-} \mathrm{C}_{2} \mathrm{H}_{4}, \mathrm{IL}_{-} \mathrm{C}_{2} \mathrm{H}_{6}$ systems. As mentioned in Section 2.3, the common UNIFAC group parameters $\left(\mathrm{CO}_{2}, \mathrm{CH}_{4}, \mathrm{C}_{2} \mathrm{H}_{4}\right.$ with $\mathrm{CH}_{2}$ and $\mathrm{CH}_{2}$ with $\mathrm{CH}_{2} \mathrm{O}$ ) reported in the literature Nocon et al., (1983; Skjoldjorgensen et al., (1979) have been used directly in this work.

The obtained UNIFAC parameters are summarized and shown in Fig. 5. The comparison between experimental and calculated values for the infinite dilution activity coefficients of IL- $\mathrm{CO}_{2}$ and IL-CH $\mathrm{CH}_{4}$ systems is shown in Fig. 6. And the systems of $\mathrm{IL}-\mathrm{C}_{2} \mathrm{H}_{4}$ and $\mathrm{IL}-\mathrm{C}_{2} \mathrm{H}_{6}$ which have the experimental data are also compared with both corrected COSMO-RS and UNIFAC predicted values, as shown in Fig. 7, the corresponding data information can be found in Table S30 in the Supporting Information. 
Table 4 UNIFAC parameters of dimensionless group volume $R_{k}$ and surface area $Q_{k}$ used in this work

\begin{tabular}{|c|c|c|c|c|c|c|}
\hline Group No. & Main group & Subgroup & $\mathbf{R}_{\mathbf{k}}$ & $\mathbf{Q}_{\mathrm{k}}$ & $\begin{array}{c}\text { Reference } \\
\text { source }\end{array}$ & Structure \\
\hline 1 & $\mathrm{CO}_{2}$ & $\mathrm{CO}_{2}$ & 1.3000 & 1.1200 & $\begin{array}{c}\text { Nocon et al., } \\
\text { (1983) }\end{array}$ & \\
\hline 2 & $\mathrm{CH}_{4}$ & $\mathrm{CH}_{4}$ & 1.1290 & 1.1240 & $\begin{array}{c}\text { Nocon et al., } \\
\text { (1983) }\end{array}$ & \\
\hline 3 & $\mathrm{C}_{2} \mathrm{H}_{4}$ & $\mathrm{C}_{2} \mathrm{H}_{4}$ & 1.5740 & 1.4880 & $\begin{array}{l}\text { Nocon et al., } \\
\text { (1983) }\end{array}$ & \\
\hline 4 & $\mathrm{C}_{2} \mathrm{H}_{6}$ & $\mathrm{C}_{2} \mathrm{H}_{6}$ & 1.8022 & 1.6960 & $\begin{array}{c}\text { Dahl et al., } \\
\text { (1991) }\end{array}$ & \\
\hline 5 & $\mathrm{CH}_{2}$ & $\mathrm{CH}_{3}$ & 0.9011 & 0.8480 & $\begin{array}{c}\text { Fredenslund et } \\
\text { al., (1975) }\end{array}$ & \\
\hline & & $\mathrm{CH}_{2}$ & 0.6744 & 0.5400 & $\begin{array}{l}\text { Fredenslund et } \\
\text { al., (1975) }\end{array}$ & \\
\hline 6 & $\mathrm{CH}_{2} \mathrm{O}$ & $\mathrm{CH}_{2} \mathrm{O}$ & 0.9183 & 0.7800 & $\begin{array}{c}\text { Lei et al., } \\
\text { (2009) }\end{array}$ & \\
\hline 7 & [IM] & [IM] & 1.9471 & 0.8660 & $\begin{array}{l}\text { Roughton et } \\
\text { al., (2012) }\end{array}$ & \\
\hline \multirow{3}{*}{8} & \multirow{3}{*}{ [PY] } & [MIM] & 2.8482 & 1.7140 & $\begin{array}{l}\text { Roughton et } \\
\text { al., (2012) }\end{array}$ & \\
\hline & & {$[\mathrm{PY}]$} & 2.6670 & 1.5530 & $\begin{array}{l}\text { Roughton et } \\
\text { al., (2012) }\end{array}$ & \multirow[b]{3}{*}{ - أ- } \\
\hline & & [MPY] & 3.5681 & 2.4010 & $\begin{array}{l}\text { Roughton et } \\
\text { al., (2012) }\end{array}$ & \\
\hline 9 & {$\left[\mathrm{BF}_{4}\right]$} & {$\left[\mathrm{BF}_{4}\right]$} & 1.7856 & 1.4940 & $\begin{array}{l}\text { Roughton et } \\
\text { al., (2012) }\end{array}$ & \\
\hline 10 & {$\left[\mathrm{PF}_{6}\right]$} & {$\left[\mathrm{PF}_{6}\right]$} & 7.0615 & 6.5787 & $\begin{array}{l}\text { Roughton et } \\
\text { al., (2012) }\end{array}$ & \\
\hline 11 & {$\left[\mathrm{Tf}_{2} \mathrm{~N}\right]$} & {$\left[\mathrm{Tf}_{2} \mathrm{~N}\right]$} & 5.7738 & 4.9320 & $\begin{array}{l}\text { Roughton et } \\
\text { al., (2012) }\end{array}$ & \\
\hline 12 & {$[\mathrm{Br}]$} & {$[\mathrm{Br}]$} & 0.9492 & 0.8320 & $\begin{array}{l}\text { Roughton et } \\
\text { al., (2012) }\end{array}$ & \\
\hline 13 & {$[\mathrm{SCN}]$} & {$[\mathrm{SCN}]$} & 1.9446 & 1.1752 & $\begin{array}{l}\text { Roughton et } \\
\text { al., (2012) }\end{array}$ & \\
\hline 14 & {$\left[\mathrm{CH}_{3} \mathrm{SO}_{4}\right]$} & {$\left[\mathrm{CH}_{3} \mathrm{SO}_{4}\right]$} & 3.4832 & 3.7280 & $\begin{array}{l}\text { Roughton et } \\
\text { al., (2012) }\end{array}$ & \\
\hline 15 & [DCA] & {$[\mathrm{DCA}]$} & 2.4171 & 2.1337 & $\begin{array}{c}\text { Song et al., } \\
\text { (2018) }\end{array}$ & $\mathrm{N} \equiv \mathrm{c}$ \\
\hline 16 & {$\left[\mathrm{NO}_{3}\right]$} & {$\left[\mathrm{NO}_{3}\right]$} & 1.6611 & 1.5289 & $\begin{array}{c}\text { Song et al., } \\
\text { (2018) }\end{array}$ & \\
\hline 17 & {$[\mathrm{Cl}]$} & {$[\mathrm{Cl}]$} & 0.7660 & 0.7200 & Roughton et & \\
\hline
\end{tabular}




\begin{tabular}{|c|c|c|c|c|c|c|}
\hline & & & & & al., (2012) & \\
\hline 18 & [TfO] & {$[\mathrm{TfO}]$} & 3.4745 & 2.9796 & $\begin{array}{c}\text { Song et al., } \\
\text { (2018) }\end{array}$ & \\
\hline 19 & [eFAP] & [eFAP] & 9.4117 & 7.7294 & $\begin{array}{c}\text { Song et al., } \\
\text { (2018) }\end{array}$ & \\
\hline
\end{tabular}

Table 5 Order of optimization and the corresponding AARD values between experimental or corrected COSMO-RS value and estimated infinite dilution activity coefficients from UNIFAC

\begin{tabular}{|c|c|c|c|}
\hline $\begin{array}{l}\text { Sequence } \\
\text { of fitting }\end{array}$ & Systems & $\begin{array}{l}\text { Number of data points used } \\
\text { in parameter regression }\end{array}$ & $\begin{array}{c}\text { AARD of each } \\
\text { system }(\%)\end{array}$ \\
\hline 1 & 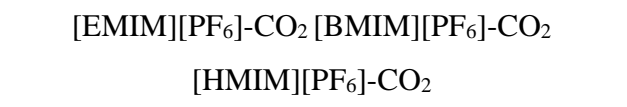 & 231 & 6.1 \\
\hline 2 & 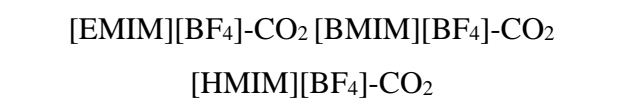 & 121 & 13.4 \\
\hline 3 & {$[\mathrm{BPY}]\left[\mathrm{BF}_{4}\right]-\mathrm{CO}_{2}$} & 12 & 12.2 \\
\hline 4 & $\begin{array}{c}{[\mathrm{EMIM}]\left[\mathrm{Tf}_{2} \mathrm{~N}\right]-\mathrm{CO}_{2}[\mathrm{BMIM}]\left[\mathrm{Tf}_{2} \mathrm{~N}\right]-\mathrm{CO}_{2}} \\
{[\mathrm{HMIM}]\left[\mathrm{Tf}_{2} \mathrm{~N}\right]-\mathrm{CO}_{2}}\end{array}$ & 167 & 11.4 \\
\hline 5 & {$\left[(\mathrm{ETO})_{2} \mathrm{IM}\right]\left[\mathrm{Tf}_{2} \mathrm{~N}\right]-\mathrm{CO}_{2}$} & 16 & 6.0 \\
\hline 6 & {$[\mathrm{BMIM}]\left[\mathrm{CH}_{3} \mathrm{SO}_{4}\right]-\mathrm{CO}_{2}[\mathrm{HMIM}]\left[\mathrm{CH}_{3} \mathrm{SO}_{4}\right]-\mathrm{CO}_{2}$} & 40 & 15.1 \\
\hline 7 & $\begin{array}{c}{[\mathrm{EMIM}][\mathrm{TfO}]-\mathrm{CO}_{2}[\mathrm{BMIM}][\mathrm{TfO}]-\mathrm{CO}_{2}[\mathrm{HMIM}][} \\
\mathrm{TfO}]-\mathrm{CO}_{2}\end{array}$ & 82 & 14.8 \\
\hline 8 & {$[\mathrm{EMIM}][\mathrm{DCA}]-\mathrm{CO}_{2}[\mathrm{BMIM}][\mathrm{DCA}]-\mathrm{CO}_{2}$} & 30 & 11.2 \\
\hline 9 & {$[\mathrm{BMIM}][\mathrm{SCN}]-\mathrm{CO}_{2}$} & 34 & 12.0 \\
\hline 10 & {$[\mathrm{MMIM}][\mathrm{DMP}]-\mathrm{CO}_{2}$} & 12 & 1.7 \\
\hline 11 & {$[\mathrm{BMIM}]\left[\mathrm{NO}_{3}\right]-\mathrm{CO}_{2}$} & 54 & 6.8 \\
\hline 12 & {$[\mathrm{BMIM}][\mathrm{Cl}]-\mathrm{CO}_{2}$} & 15 & 9.7 \\
\hline 13 & {$[\mathrm{BMIM}][\mathrm{eFAP}]-\mathrm{CO}_{2}$} & 15 & 2.9 \\
\hline & $\begin{array}{l}\text { Total No. of data points and total AARD of } \\
\qquad{\mathrm{IL}-\mathrm{CO}_{2} \text { systems }}^{\text {. }}\end{array}$ & 829 & 9.5 \\
\hline 14 & {$[\mathrm{BMIM}]\left[\mathrm{PF}_{6}\right]-\mathrm{CH}_{4}$} & 74 & 25.2 \\
\hline 15 & {$[\mathrm{BMIM}]\left[\mathrm{BF}_{4}\right]-\mathrm{CH}_{4}$} & 8 & 5.9 \\
\hline 16 & {$[\mathrm{BMIM}]\left[\mathrm{Tf}_{2} \mathrm{~N}\right]-\mathrm{CH}_{4}[\mathrm{HMIM}]\left[\mathrm{Tf}_{2} \mathrm{~N}\right]-\mathrm{CH}_{4}$} & 16 & 31.9 \\
\hline 17 & {$[\mathrm{HMPY}]\left[\mathrm{Tf}_{2} \mathrm{~N}\right]-\mathrm{CH}_{4}$} & 84 & 27.8 \\
\hline 18 & {$[\mathrm{BMIM}]\left[\mathrm{CH}_{3} \mathrm{SO}_{4}\right]-\mathrm{CH}_{4}$} & 10 & 30.5 \\
\hline 19 & {$[\mathrm{BMIM}][\mathrm{DCA}]-\mathrm{CH}_{4}$} & 14 & 31.3 \\
\hline \multirow[t]{2}{*}{20} & {$[\mathrm{EMIM}][\mathrm{eFAP}]-\mathrm{CH}_{4}$} & 23 & 29.2 \\
\hline & 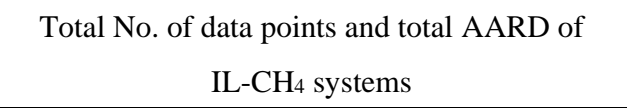 & 229 & 26.0 \\
\hline
\end{tabular}




\begin{tabular}{|c|c|c|c|}
\hline 21 & $\begin{array}{c}{[\mathrm{EMIM}]\left[\mathrm{PF}_{6}\right]-\mathrm{C}_{2} \mathrm{H}_{4}[\mathrm{BMIM}]\left[\mathrm{PF}_{6}\right]-\mathrm{C}_{2} \mathrm{H}_{4}} \\
{[\mathrm{HMIM}]\left[\mathrm{PF}_{6}\right]-\mathrm{C}_{2} \mathrm{H}_{4}}\end{array}$ & 30 & 1.6 \\
\hline 22 & $\begin{array}{c}{[\mathrm{EMIM}]\left[\mathrm{BF}_{4}\right]-\mathrm{C}_{2} \mathrm{H}_{4}[\mathrm{BMIM}]\left[\mathrm{BF}_{4}\right]-\mathrm{C}_{2} \mathrm{H}_{4}} \\
{[\mathrm{HMIM}]\left[\mathrm{BF}_{4}\right]-\mathrm{C}_{2} \mathrm{H}_{4}}\end{array}$ & 30 & 22.6 \\
\hline 23 & $\begin{array}{c}{[E M I M]\left[\mathrm{Tf}_{2} \mathrm{~N}\right]-\mathrm{C}_{2} \mathrm{H}_{4}[\mathrm{BMIM}]\left[\mathrm{Tf}_{2} \mathrm{~N}\right]-\mathrm{C}_{2} \mathrm{H}_{4}} \\
{[\mathrm{HMIM}]\left[\mathrm{Tf}_{2} \mathrm{~N}\right]-\mathrm{C}_{2} \mathrm{H}_{4}}\end{array}$ & 30 & 14.3 \\
\hline 24 & $\begin{array}{c}{[\mathrm{EMIM}]\left[\mathrm{CH}_{3} \mathrm{SO}_{4}\right]-\mathrm{C}_{2} \mathrm{H}_{4}[\mathrm{BMIM}]\left[\mathrm{CH}_{3} \mathrm{SO}_{4}\right]-} \\
\mathrm{C}_{2} \mathrm{H}_{4}[\mathrm{HMIM}]\left[\mathrm{CH}_{3} \mathrm{SO}_{4}\right]-\mathrm{C}_{2} \mathrm{H}_{4}\end{array}$ & 30 & 24.1 \\
\hline 25 & $\begin{array}{c}{[\text { EMIM }][\text { TfO }]-\mathrm{C}_{2} \mathrm{H}_{4}[\mathrm{BMIM}][\mathrm{TfO}]-\mathrm{C}_{2} \mathrm{H}_{4}} \\
{[\mathrm{HMIM}][\mathrm{TfO}]-\mathrm{C}_{2} \mathrm{H}_{4}}\end{array}$ & 30 & 12.7 \\
\hline 26 & $\begin{array}{c}{[\text { EMIM }][D C A]-\mathrm{C}_{2} \mathrm{H}_{4}[\mathrm{BMIM}][\mathrm{DCA}]-\mathrm{C}_{2} \mathrm{H}_{4}} \\
{[\mathrm{HMIM}][\mathrm{DCA}]-\mathrm{C}_{2} \mathrm{H}_{4}}\end{array}$ & 30 & 19.0 \\
\hline 27 & $\begin{array}{c}{[\mathrm{EMIM}][\mathrm{SCN}]-\mathrm{C}_{2} \mathrm{H}_{4}[\mathrm{BMIM}][\mathrm{SCN}]-\mathrm{C}_{2} \mathrm{H}_{4}} \\
{[\mathrm{HMIM}][\mathrm{SCN}]-\mathrm{C}_{2} \mathrm{H}_{4}}\end{array}$ & 30 & 31.6 \\
\hline 28 & $\begin{array}{c}{[\mathrm{EMIM}][\mathrm{DMP}]-\mathrm{C}_{2} \mathrm{H}_{4}[\mathrm{BMIM}][\mathrm{DMP}]-\mathrm{C}_{2} \mathrm{H}_{4}} \\
{[\mathrm{HMIM}][\mathrm{DMP}]-\mathrm{C}_{2} \mathrm{H}_{4}}\end{array}$ & 30 & 17.8 \\
\hline 29 & $\begin{array}{c}{[\mathrm{EMIM}][\mathrm{eFAP}]-\mathrm{C}_{2} \mathrm{H}_{4}[\mathrm{BMIM}][\mathrm{eFAP}]-\mathrm{C}_{2} \mathrm{H}_{4}} \\
{[\mathrm{HMIM}][\mathrm{eFAP}]-\mathrm{C}_{2} \mathrm{H}_{4}}\end{array}$ & 30 & 15.3 \\
\hline \multirow[t]{2}{*}{30} & $\begin{array}{c}{[E M P Y]\left[\mathrm{Tf}_{2} \mathrm{~N}\right]-\mathrm{C}_{2} \mathrm{H}_{4}[\mathrm{BMPY}]\left[\mathrm{Tf}_{2} \mathrm{~N}\right]-\mathrm{C}_{2} \mathrm{H}_{4}} \\
{[\mathrm{HMPY}]\left[\mathrm{Tf}_{2} \mathrm{~N}\right]-\mathrm{C}_{2} \mathrm{H}_{4}}\end{array}$ & 30 & 15.4 \\
\hline & $\begin{array}{l}\text { Total No. of data points and total AARD of } \\
\qquad \mathrm{IL}_{-} \mathrm{C}_{2} \mathrm{H}_{4} \text { systems }\end{array}$ & 300 & 17.4 \\
\hline 31 & $\begin{array}{c}{[\mathrm{EMIM}]\left[\mathrm{BF}_{4}\right]-\mathrm{C}_{2} \mathrm{H}_{6}[\mathrm{BMIM}]\left[\mathrm{BF}_{4}\right]-\mathrm{C}_{2} \mathrm{H}_{6}} \\
{[\mathrm{HMIM}]\left[\mathrm{BF}_{4}\right]-\mathrm{C}_{2} \mathrm{H}_{6}}\end{array}$ & 30 & 4.5 \\
\hline 32 & $\begin{array}{c}{[\mathrm{EMIM}]\left[\mathrm{PF}_{6}\right]-\mathrm{C}_{2} \mathrm{H}_{6}[\mathrm{BMIM}]\left[\mathrm{PF}_{6}\right]-\mathrm{C}_{2} \mathrm{H}_{6}} \\
{[\mathrm{HMIM}]\left[\mathrm{PF}_{6}\right]-\mathrm{C}_{2} \mathrm{H}_{6}}\end{array}$ & 30 & 5.0 \\
\hline 33 & $\begin{array}{c}{[\mathrm{EMIM}]\left[\mathrm{Tf}_{2} \mathrm{~N}\right]-\mathrm{C}_{2} \mathrm{H}_{6}[\mathrm{BMIM}]\left[\mathrm{Tf}_{2} \mathrm{~N}\right]-\mathrm{C}_{2} \mathrm{H}_{6}} \\
{[\mathrm{HMIM}]\left[\mathrm{Tf}_{2} \mathrm{~N}\right]-\mathrm{C}_{2} \mathrm{H}_{6}}\end{array}$ & 30 & 31.2 \\
\hline 34 & $\begin{array}{c}{[\mathrm{EMIM}]\left[\mathrm{CH}_{3} \mathrm{SO}_{4}\right]-\mathrm{C}_{2} \mathrm{H}_{6}[\mathrm{BMIM}]\left[\mathrm{CH}_{3} \mathrm{SO}_{4}\right]-} \\
\mathrm{C}_{2} \mathrm{H}_{6}[\mathrm{HMIM}]\left[\mathrm{CH}_{3} \mathrm{SO}_{4}\right]-\mathrm{C}_{2} \mathrm{H}_{6}\end{array}$ & 30 & 26.8 \\
\hline 35 & $\begin{array}{c}{[\mathrm{EMIM}][\mathrm{TfO}]-\mathrm{C}_{2} \mathrm{H}_{6}[\mathrm{BMIM}][\mathrm{TfO}]-\mathrm{C}_{2} \mathrm{H}_{6}} \\
{[\mathrm{HMIM}][\mathrm{TfO}]-\mathrm{C}_{2} \mathrm{H}_{6}}\end{array}$ & 30 & 39.1 \\
\hline 36 & $\begin{array}{c}{[\text { EMIM }][D C A]-\mathrm{C}_{2} \mathrm{H}_{6}[\mathrm{BMIM}][\mathrm{DCA}]-\mathrm{C}_{2} \mathrm{H}_{6}} \\
{[\mathrm{HMIM}][\mathrm{DCA}]-\mathrm{C}_{2} \mathrm{H}_{6}}\end{array}$ & 30 & 39.9 \\
\hline 37 & $\begin{array}{c}{[\mathrm{EMIM}][\mathrm{SCN}]-\mathrm{C}_{2} \mathrm{H}_{6}[\mathrm{BMIM}][\mathrm{SCN}]-\mathrm{C}_{2} \mathrm{H}_{6}} \\
{[\mathrm{HMIM}][\mathrm{SCN}]-\mathrm{C}_{2} \mathrm{H}_{6}}\end{array}$ & 30 & 40.0 \\
\hline 38 & $\begin{array}{c}{[\mathrm{EMIM}][\mathrm{DMP}]-\mathrm{C}_{2} \mathrm{H}_{6}[\mathrm{BMIM}][\mathrm{DMP}]-\mathrm{C}_{2} \mathrm{H}_{6}} \\
{[\mathrm{HMIM}][\mathrm{DMP}]-\mathrm{C}_{2} \mathrm{H}_{6}}\end{array}$ & 30 & 19.2 \\
\hline 39 & $\begin{array}{c}{[\mathrm{EMIM}][\mathrm{eFAP}]-\mathrm{C}_{2} \mathrm{H}_{6}[\mathrm{BMIM}][\mathrm{eFAP}]-\mathrm{C}_{2} \mathrm{H}_{6}} \\
{[\mathrm{HMIM}][\mathrm{eFAP}]-\mathrm{C}_{2} \mathrm{H}_{6}}\end{array}$ & 30 & 21.1 \\
\hline \multirow[t]{2}{*}{40} & $\begin{array}{c}{[E M P Y]\left[\mathrm{Tf}_{2} \mathrm{~N}\right]-\mathrm{C}_{2} \mathrm{H}_{6}[\mathrm{BMPY}]\left[\mathrm{Tf}_{2} \mathrm{~N}\right]-\mathrm{C}_{2} \mathrm{H}_{6}} \\
{[\mathrm{HMPY}]\left[\mathrm{Tf}_{2} \mathrm{~N}\right]-\mathrm{C}_{2} \mathrm{H}_{6}}\end{array}$ & 30 & 14.1 \\
\hline & $\begin{array}{l}\text { Total No. of data points and total AARD of } \\
\qquad \mathrm{IL}_{-} \mathrm{C}_{2} \mathrm{H}_{6} \text { systems }\end{array}$ & 300 & 24.1 \\
\hline
\end{tabular}




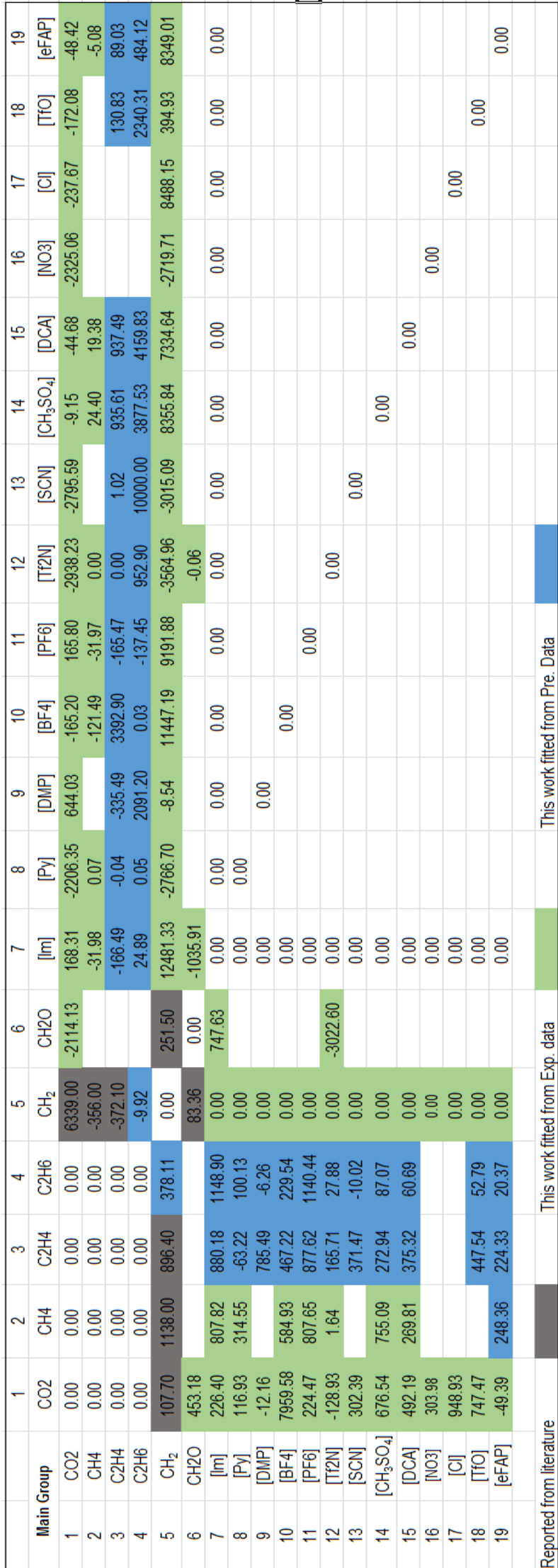

Fig. 5. Fitted UNIFAC-IL group interaction parameters (Reported values from Ref.[42; 43];Pre.=Predicted data from COSMO-RS) 


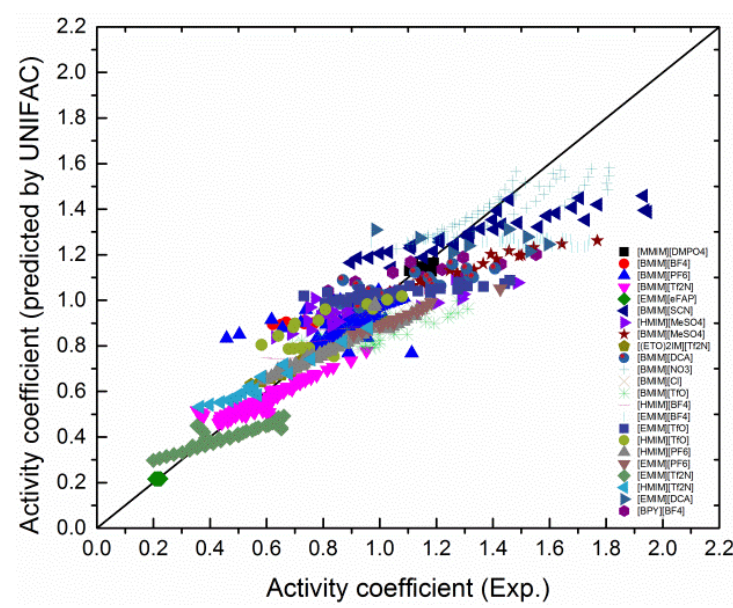

(a)

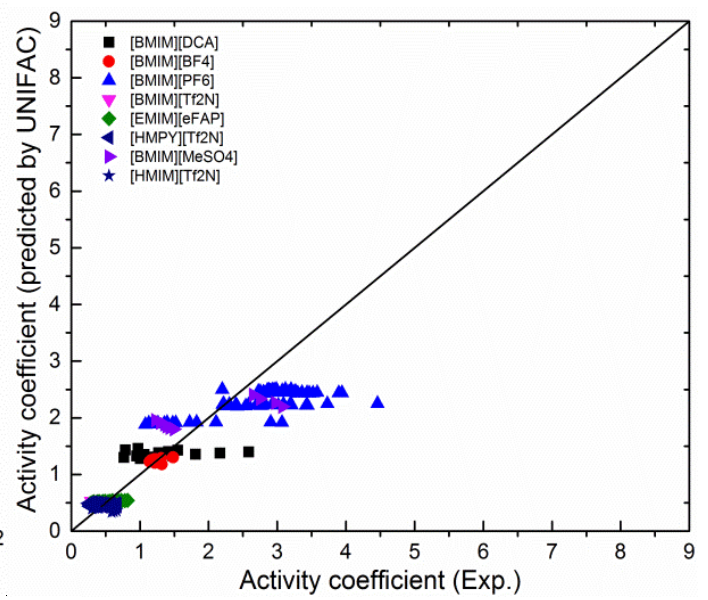

(b)

Fig. 6. Experimental $\gamma_{\text {exp }}^{\infty}$ versus UNIFAC calculated infinite dilution activity coefficients $\gamma_{U N I F A C}^{\infty}$; a) IL-CO $\mathrm{CO}_{2}$ systems, b) IL-CH 4 systems

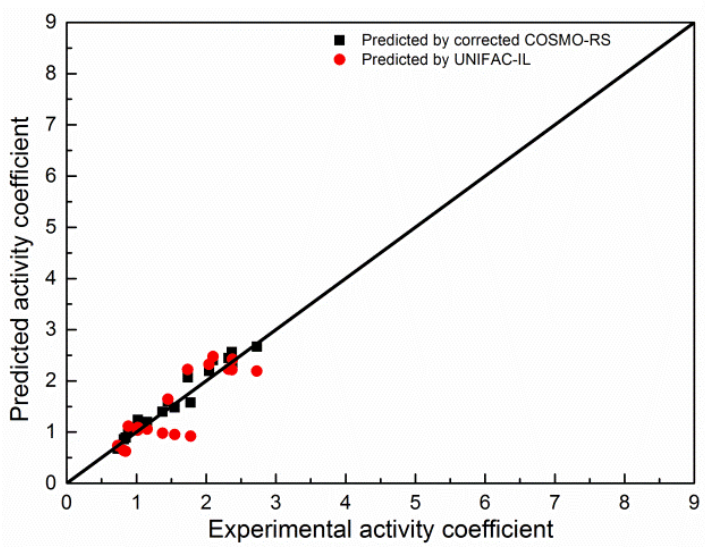

(a)

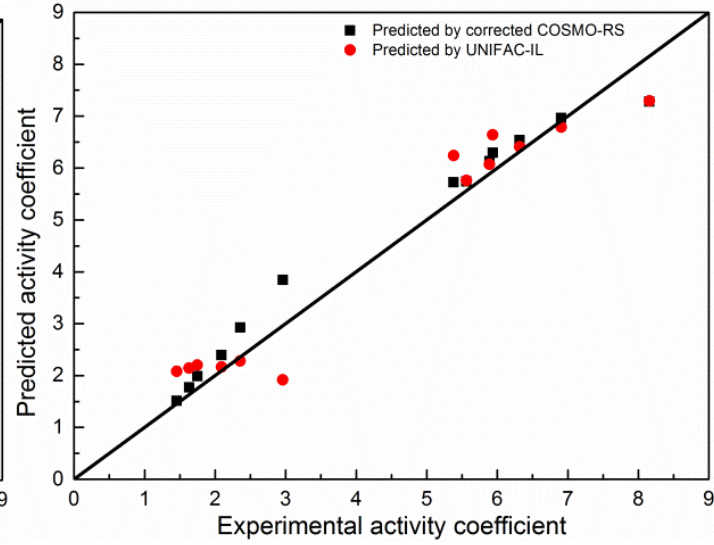

(b)

Fig. 7. Experimental $\gamma_{\exp }^{\infty}$ versus both Predicted $\gamma_{\text {cor_cosmo }}^{\infty}$ and UNIFAC calculated infinite dilution activity coefficients $\gamma_{U N I F A C}^{\infty}$; a) IL- $\mathrm{C}_{2} \mathrm{H}_{4}$ systems, b) IL- $\mathrm{C}_{2} \mathrm{H}_{6}$ systems

As a result, the UNIFAC-IL model for the four-component shale gas $\left(\mathrm{CH}_{4}, \mathrm{C}_{2} \mathrm{H}_{4}, \mathrm{C}_{2} \mathrm{H}_{6}, \mathrm{CO}_{2}\right)$ with various ILs (combined between two kinds of cation and 11 anions) systems is developed. The results predicted by the UNIFAC-IL model and the experimental data exhibit similar trends (see Fig.5 and 6), with the AARD 9.5\%, 26.0\%, 17.3\%, 14.6\% for $\mathrm{IL}_{-} \mathrm{CO}_{2}, \mathrm{IL}_{-} \mathrm{CH}_{4}, \mathrm{IL}_{-} \mathrm{C}_{2} \mathrm{H}_{4}$ and IL- $\mathrm{C}_{2} \mathrm{H}_{6}$ systems, respectively.

For IL-CH 4 system (see Fig.5b), there exists relatively large deviation. A general reason for this is that same group parameters from IL- $\mathrm{CO}_{2}$ systems are directly used for IL-CH $4, \mathrm{IL}_{2} \mathrm{C}_{2} \mathrm{H}_{4}$ and also IL- $\mathrm{C}_{2} \mathrm{H}_{6}$, it is difficult to obtain a global optimization result. Most in details, the reasons on the largest deviation for the $\mathrm{IL}_{-} \mathrm{CH}_{4}$ systems (AARD $=26 \%$ ) and the calculated activity coefficients change little at same temperature for each system (seen Fig. 6b) are as follows: 1) the low solubility of $\mathrm{CH}_{4}$ in ILs; 2) limited solubility data of $\mathrm{CH}_{4}$ in ILs and some solubility data under a wide range of pressure used for correlation; 3) for some ILs, the experimental data from more than one data sources, with some deviations from each other. Nevertheless, compared with 
an average deviation of about $50 \%$ for the corrected COSMO-RS model for the $\mathrm{IL}_{-} \mathrm{CH}_{4}$ systems, the predicted results by UNIFAC are in quantitatively better agreement with the experimental data. For IL- $\mathrm{C}_{2} \mathrm{H}_{4}$ and IL- $\mathrm{C}_{2} \mathrm{H}_{6}$ systems, because of the UNIFAC model is developed based on the corrected COSMO-RS values, the AARD of UNIFAC with experiments is a little bit larger than that of the corrected COSMO-RS $(6.3 \%, 8.9 \%)$, but this UNIFAC model is easier available without any quantum chemical calculation.

In addition, this group division method provides the possibility for further IL screening and design for the shale gas separation. With these group interaction parameters, the activity coefficient of each gas in different combinations of cation, anion, and the substitutes can be easily estimated. Then, the IL with high solubility of $\mathrm{CO}_{2}$ and high selectivity of $\mathrm{CO}_{2}$ or other two light hydrocarbon gases to $\mathrm{CH}_{4}$ can be screened out. This will be illustrated in a subsequent publication.

\section{Conclusion and future perspectives}

This work establishes first of all a database containing sufficient experimental data for Henry's law constant and solubility of several gases in ILs. Especially, as they are the conventional components of shale gas, measured data of $\mathrm{CO}_{2}$ and three light hydrocarbon gases $\left(\mathrm{CH}_{4}, \mathrm{C}_{2} \mathrm{H}_{4}\right.$, and $\left.\mathrm{C}_{2} \mathrm{H}_{6}\right)$, together with some validated predicted values from a corrected COSMO-RS model, are included in the database. This database is used for the further development of UNIFAC-IL, and then the performance of both corrected COSMO-RS and UNIFAC-IL model is evaluated.

As our focus is on ILs screening and prediction purposes for shale gas separation, a UNIFAC-IL model is developed for the predictions of solubility of four shale gases $\left(\mathrm{CH}_{4}, \mathrm{C}_{2} \mathrm{H}_{4}\right.$, $\mathrm{C}_{2} \mathrm{H}_{6}, \mathrm{CO}_{2}$ ) in ILs. Because of insufficient available experimental data for $\mathrm{IL}_{-} \mathrm{C}_{2} \mathrm{H}_{4}$ and IL- $\mathrm{C}_{2} \mathrm{H}_{6}$ systems, the COSMO-RS model is considered and validated as a supplementary tool for generation of additional data for $\mathrm{C}_{2} \mathrm{H}_{4}$ and $\mathrm{C}_{2} \mathrm{H}_{6}$ solubility in more ILs. In the first case, we have developed a corrected version of COSMO-RS model for all the four gases and a good prediction is obtained for the activity coefficient of $\mathrm{C}_{2} \mathrm{H}_{4}$ and $\mathrm{C}_{2} \mathrm{H}_{6}$ in ILs, with the average absolute relative deviation (AARD) of $6.2 \%$ and $8.9 \%$, respectively. Then based on 600 predicted activity coefficient data points for $\mathrm{C}_{2} \mathrm{H}_{4}, \mathrm{C}_{2} \mathrm{H}_{6}$ in ILs and sufficient measured solubility data of $\mathrm{CO}_{2}, \mathrm{CH}_{4}$ in ILs, the UNIFAC-IL model is developed and interaction parameters between these four gases and 15 main groups presented in conventional ILs have been determined. The AARDs between calculated activity coefficients and experiments for the IL- $\mathrm{CO}_{2}, \mathrm{IL}-\mathrm{CH}_{4}, \mathrm{IL}_{-} \mathrm{C}_{2} \mathrm{H}_{4}$ and IL- $\mathrm{C}_{2} \mathrm{H}_{6}$ systems are about $9.5 \%, 26.0 \%, 17.4 \%, 14.6 \%$ respectively. It is found that the proposed corrected version of the COSMO-RS model is able to predict the Henry's law constants of $\mathrm{C}_{2} \mathrm{H}_{4}$ and $\mathrm{C}_{2} \mathrm{H}_{6}$ in ILs, whereas for the cases of $\mathrm{CO}_{2}$ and $\mathrm{CH}_{4}$ where there is sufficient experimental data, the regressed UNIFAC-IL model performs better than COSMO-RS. Moreover, the developed UNIFAC-IL model can be used to predict the solubility of gases in new ILs that are not included in parameter fitting due to its group contribution basis. For this reason, the model represents a very useful tool for task-specific design of ionic liquids for gas separations.

This work provides a good basis for ILs screening and the basis of group contribution in UNIFAC makes it very useful for further IL design on shale gas separation processes, in which a systematic three-stage framework toward IL-based gas separation will be proposed and a hybrid IL-based process will be established. 


\section{Acknowledgements}

Financial support received from National Key R\&D Program of China (2017YFB0603301); the joint project from Institute of Process Engineering Chinese Academy of Sciences and Department of Chemical and Biochemical Engineering in Technical University of Denmark; National Natural Science Funds for Distinguished Young Scholar (No.21425625); General Program of National Natural Science Foundation of China; and Chinese Academy of Sciences State Administration of Foreign Experts Affairs (CAS/SAFEA) International Partnership Program for Creative Research Teams (No.20140491518).

\section{Appendix A.UNIFAC}

In UNIFAC, the activity coefficient consists of a combinatorial part and a residual part, as shown in Eq. (A.1)

$$
\ln \gamma_{i}^{U N I F A C}=\ln \gamma_{i}^{C}+\ln \gamma_{i}^{R}
$$

The combinatorial part is given by the following equations:

$$
\begin{gathered}
\ln \gamma_{i}^{C}=1-V_{i}+\ln V_{i}-5 q_{i}\left(1-\frac{V_{i}}{F_{i}}+\ln \left(\frac{V_{i}}{F_{i}}\right)\right) \\
F_{i}=\frac{q_{i}}{\sum_{j} q_{j} x_{j}} \quad V_{i}=\frac{r_{i}}{\sum_{j} r_{j} x_{j}} \\
r_{i}=\sum_{k} v_{k}^{(i)} R_{k} \quad q_{i}=\sum_{k} v_{k}^{(i)} Q_{k}
\end{gathered}
$$

Where $R_{k}$ and $Q_{k}$ are the relative van der Waals group volumes and group surface areas, respectively. $r_{i}$ and $q_{i}$ are the dimensionless molecular van der Waals volumes and surface areas, which are calculated from the summation of group volumes and surface areas, respectively.

The residual part is determined by the equations:

$$
\begin{gathered}
\ln \gamma_{i}^{R}=\sum_{k} v_{k}^{(i)}\left(\ln \Gamma_{k}-\ln \Gamma_{k}^{(i)}\right) \\
\ln \Gamma_{k}=Q_{k}\left[1-\ln \left(\sum_{m} \Theta_{m} \psi_{m k}\right)-\sum_{m}\left(\frac{\Theta_{m} \psi_{k m}}{\sum_{n} \Theta_{n} \psi_{n m}}\right)\right] \\
X_{m}=\frac{\sum_{i} v_{m}^{(i)} x_{i}}{\sum_{i} \sum_{k} v_{k}^{(i)} x_{i}} \quad \Theta_{m}^{(i)}=\frac{Q_{m} X_{m}^{(i)}}{\sum_{n} Q_{n} X_{n}^{(i)}} \quad \Theta_{m}=\frac{Q_{m} X_{m}}{\sum_{n} Q_{n} X_{n}} \\
\psi_{m n}=\exp \left(-\frac{a_{m n}}{T}\right) \quad \psi_{n m}=\exp \left(-\frac{a_{n m}}{T}\right)
\end{gathered}
$$

Where $\Gamma_{k}$ is the group residual activity coefficient and $\Gamma_{k}^{(i)}$ is the residual activity coefficient of group $\mathrm{k}$ in a reference solution containing only compound $i . X_{m}$ is the fraction of 
group $\mathrm{m}$ in the mixture. $\psi_{m n}$ is the group interaction parameter. $a_{m n}$ characterizes the interaction energy between groups $n$ and $m$.

Appendix B. Supplementary information

Supplementary information associated with this article can be found in the online version.

Abbreviations

COSMO-RS

Conductor-like Screening Model for Real Solvents

ILs

Ionic liquids

MEA

Monoethanolamine

MDEA

Methyldiethanolamine

DEA

Diethanolamine

EoS

Equation of state

UNIFAC

Universal quasichemical functional-group activity coefficients

CAMD

Computer-aided molecular design

QC

Quantum chemical

SCD

Surface charge density

AARD

Average absolute relative deviation

[EMIM]

1-ethyl-3-methylimidazolium

[BMIM]

1-butyl-3-methylimidazolium

[HMIM]

1-hexyl-3-methylimidazolium

[MMIM]

1,3-dimethyl-imidazolium

[OMIM]

1-octyl-3-methylimidazolium

[AMIM]

1-allyl-3-methylimidazolium

[BMPYRR]

1-butyl-1-methylpyrrolidinium

[thtdp]

Tributyl(tetradecyl)phosphonium

[BMPIP]

1-butyl-1-methylpiperidinium

[tes]

Triethylsulfonium

[toa]

Methyltrioctylammonium

[DCA]

Dicyanamide

$\left[\mathrm{PF}_{6}\right]$

Hexafluorophosphate 


\section{LIST OF SYMBOLS}

$p_{i}^{S}=$ vapor pressure of pure component $i$

$P=$ pressure, $\mathrm{Pa}$

$T=$ temperature, $\mathrm{K}$

$x_{i}=$ composition of component $i$ in liquid

$y_{i}=$ composition of component $i$ in vapor

$\gamma_{i}=$ activity coefficient

$E_{\text {misfit }}=$ misfit energy of two molecules.

$\alpha^{\prime}=$ energy factor.

$\sigma=$ charge density, Coulomb $/ \mathrm{m}^{2}$

$a_{e f f}=$ contacted surface area, $\mathrm{m}^{2}$

$E_{h b}=$ hydrogen interaction energy, Coulomb

$\mu_{i}=$ chemical potential.

$E_{v d W}=$ interaction energy attributing to van der Waals force

$p_{i}(\sigma)=$ probability distribution of $\sigma$

$H_{i A}=$ Henry's law constant of component $i$ in solvent $\mathrm{A}, \mathrm{Pa}$

$\gamma_{i}^{\infty}=$ the infinite dilution activity coefficient of component $i$

$R_{k}=$ group parameters of volume

$Q_{k}=$ group parameters of surface area

$r_{i}=$ molecular van der Waals volumes 
$q_{i}=$ molecular surface area

$\Gamma_{k}=$ group residual activity coefficient

$\Gamma_{k}^{(i)}=$ residual activity coefficient of group $k$ in a reference solution containing only molecule of

type $i$.

$X_{m}=$ fraction of group $\mathrm{m}$ in the mixture

$\psi_{m n}, a_{m n}=$ interaction parameters between groups $n$ and $m$

\section{Reference}

Afkhamipour, M., \& Mofarahi, M. 2014. Sensitivity analysis of the rate-based $\mathrm{CO}_{2}$ absorber model using amine solutions (MEA, MDEA and AMP) in packed columns. Int. J. Greenhouse Gas Control, 25, 9-22. doi:10.1016/j.jiggc.2014.03.005

Bermejo, M. D., Martin, A., Foco, G., Cocero, M. J., Bottini, S. B., \& Peters, C. J. 2009. Application of a group contribution equation of state for the thermodynamic modeling of the binary systems CO 2 -1-butyl-3-methyl imidazolium nitrate and CO 2 -1-hydroxy-1-propyl-3-methyl imidazolium nitrate. Journal of Supercritical Fluids, 50(2), 112-117.

Blanchard, L. A., Hancu, D., Beckman, E. J., \& Brennecke, J. F. 1999. Green Processing using Ionic Liquids and $\mathrm{CO}_{2}$. Nature, 399, 28.

Blath, J., Christ, M., Deubler, N., Hirth, T., \& Schiestel, T. 2011. Gas solubilities in room temperature ionic liquids - Correlation between RTiL-molar mass and Henry's law constant. Chemical Engineering Journal, 172(1), 167-176. doi:10.1016/j.cej.2011.05.084

Bondi, A. 1964. van der Waals Volumes and Radii. Journal of Physical Chemistry, 68(3), 441-451.

Breure, B., Bottini, S. B., Witkamp, G. J., \& Peters, C. J. 2007. Thermodynamic modeling of the phase behavior of binary systems of ionic liquids and carbon dioxide with the group contribution equation of state. Journal of Physical Chemistry B, 111(51), 14265-14270.

Cao, L., Zhu, P., Zhao, Y., \& Zhao, J. 2018. Using machine learning and quantum chemistry descriptors to predict the toxicity of ionic liquids. Journal of Hazardous Materials, 352, 17-26. doi:https://doi.org/10.1016/i.jhazmat.2018.03.025

Carlisle, T. K., Bara, J. E., Gabriel, C. J., Noble, R. D., \& Gin, D. L. 2008. Interpretation of CO2 Solubility and Selectivity in Nitrile-Functionalized Room-Temperature Ionic Liquids Using a Group Contribution Approach. Industrial \& Engineering Chemistry Research, 47(18), 7005-7012.

Chávezislas, L. M., Vasquezmedrano, R., \& Florestlacuahuac, A. 2014. Optimal Molecular Design of Ionic Liquids for High-Purity Bioethanol Production. Industrial \& Engineering Chemistry Research, 50(9), 5153-5168.

Dahl, S., Fredenslund, A., \& Rasmussen, P. 1991. The MHV2 model: a UNIFAC-based equation of state model for prediction of gas solubility and vapor-liquid equilibria at low and high pressures. Industrial \& Engineering Chemistry Research, 30(8), 1936-1945.

Eckert, F. 2013. COSMOtherm_Manual: Version C3.0 Release 14.01. Imbacher Weg 46, D-51379 Leverkusen, Germany: COSMOlogic GmbH \& Co KG. 
Fallanza, M., González-Miquel, M., Ruiz, E., Ortiz, A., Gorri, D., Palomar, J., \& Ortiz, I. 2013. Screening of RTILs for propane/propylene separation using COSMO-RS methodology. Chem Eng J., 220, 284-293. doi:10.1016/j.cej.2013.01.052

Farahipour, R., Mehrkesh, A., \& Karunanithi, A. T. 2016. A systematic screening methodology towards exploration of ionic liquids for CO 2 capture processes. Chemical Engineering Science, 145, 126-132. doi:10.1016/j.ces.2015.12.015

Fredenslund, A., Jones, R. L., \& Prausnitz, J. M. 1975. Group-Contribution Estimation of Activity-Coefficients in Nonideal Liquid-Mixtures. Aiche Journal, 21(6), 1086-1099. doi:DOI 10.1002/aic.690210607

Frisch, M. J., Trucks, G. W., Schlegel, H. B., Scuseria, G. E., Robb, M. A., Cheeseman, J. R., . . Petersson, G. A. 2010. Gaussian 09, Revision B.01.

Frisch, M. J. T., Trucks, G. W., Schlegel, H. B., Scuseria, G. E. W., Robb, M. A., Cheeseman, J. R. J., . . . Burant, J. C. N. 2004. Gaussian 03, Revision B.03.

Han, J., Dai, C., Yu, G., \& Lei, Z. 2018. Parameterization of COSMO-RS model for ionic liquids. Green Energy \& Environment. doi:https://doi.org/10.1016/i.gee.2018.01.001

Hizaddin, H. F., Hadj-Kali, M. K., AlNashef, I. M., Mjalli, F. S., \& Hashim, M. A. 2015. Prediction of CO2 solubility in ionic liquids using the PSRK model. The Journal of Supercritical Fluids, 100, 184-193. doi:10.1016/j.supflu.2015.02.009

https://dippr.aiche.org/SampleDb.

Kapetaki, Z., Brandani, P., Brandani, S., \& Ahn, H. 2015. Process simulation of a dual-stage Selexol process for $95 \%$ carbon capture efficiency at an integrated gasification combined cycle power plant. International Journal of Greenhouse Gas Control, 39, 17-26. doi:https://doi.org/10.1016/j.ijggc.2015.04.015

Klamt, A., \& Eckert, F. 2000. COSMO-RS: a novel and efficient method for the a priori prediction of thermophysical data of liquids. Fluid Phase Equilibria, 172, 43-72.

Lee, B.-S., \& Lin, S.-T. 2015. Screening of Ionic Liquids for $\mathrm{CO}_{2}$ Capture using the COSMO-SAC Model. Chem. Eng. Sci., 121, 157-168. doi:10.1016/j.ces.2014.08.017

Lei, Z., Dai, C., \& Chen, B. 2014a. Gas Solubility in Ionic Liquids. Chem Rev, 114(2), 1289-1326. doi:10.1021/cr300497a

Lei, Z., Dai, C., Liu, X., Xiao, L., \& Chen, B. 2012. Extension of the UNIFAC Model for lonic Liquids. Industrial \& Engineering Chemistry Research, 51(37), 12135-12144. doi:10.1021/ie301159v

Lei, Z., Dai, C., Wang, W., \& Chen, B. 2014b. UNIFAC model for ionic liquid-CO2 systems. AIChE Journal, 60(2), 716-729. doi:10.1002/aic.14294

Lei, Z., Zhang, J., Li, Q., \& Chen, B. 2009. UNIFAC Model for lonic Liquids. Ind. Eng. Chem. Res., 48, 2697-2704.

Lyu, Z., Zhou, T., Chen, L., Ye, Y., Sundmacher, K., \& Qi, Z. 2014. Simulation based ionic liquid screening for benzene-cyclohexane extractive separation. Chemical Engineering Science, 113, 45-53. doi:https://doi.org/10.1016/i.ces.2014.04.011

Manan, N. A., Hardacre, C., Jacquemin, J., Rooney, D. W., \& Youngs, T. G. A. 2009. Evaluation of Gas Solubility Prediction in Ionic Liquids using COSMOthermX. Journal of Chemical \& Engineering Data, 54, 2005-2022.

Morales-Rodríguez, R., Gani, R., Déchelotte, S., Vacher, A., \& Baudouin, O. 2008. Use of CAPE-OPEN standards in the interoperability between modelling tools (MoT) and process simulators (Simulis ${ }^{\circledR}$; Thermodynamics and ProSimPlus). Chemical Engineering Research \& Design, 86(7), 
823-833.

Mota Martinez, M. T., Kroon, M. C., \& Peters, C. J. 2015. Modeling CO2 solubility in an ionic liquid: A comparison between a cubic and a group contribution EoS. The Journal of Supercritical Fluids, 101, 54-62. doi:10.1016/j.supflu.2015.02.024

Muldoon, M. J., Aki, S. N. V. K., Anderson, J. L., Dixon, J. N. K., \& Brennecke, J. F. 2007. Improving carbon dioxide solubility in ionic liquids. Journal of Physical Chemistry B, 111(30), 9001-9009.

Nocon, G., Weidlich, U., Gmehling, J., Menke, J., \& Onken, U. 1983. Prediction of gas solubilities by a modified UNIFAC equation. Zeitschrift Fã¹/4r Elektrochemie Berichte Der Bunsengesellschaft Fã̃1/4r Physikalische Chemie, 13(1), 381-392.

Pereira, L. M. C., Oliveira, M. B., Dias, A. M. A., Llovell, F., Vega, L. F., Carvalho, P. J., \& Coutinho, J. A. P. 2013. High pressure separation of greenhouse gases from air with 1-ethyl-3-methylimidazolium methyl-phosphonate. International Journal of Greenhouse Gas Control, 19(21), 299-309.

Roughton, B. C., Christian, B., White, J., Camarda, K. V., \& Gani, R. 2012. Simultaneous design of ionic liquid entrainers and energy efficient azeotropic separation processes. Computers \& Chemical Engineering, 42, 248-262. doi:10.1016/j.compchemeng.2012.02.021

Santiago, R. S., \& Aznar, M. 2011. Liquid-liquid equilibrium in ternary ionic liquid systems by UNIFAC: New volume, surface area and interaction parameters. Part II. Fluid Phase Equilibria, 295(1), 93-97.

Santiago, R. S., Santos, G. R., \& Aznar, M. 2010. Liquid-liquid equilibrium in ternary ionic liquid systems by UNIFAC: New volume, surface area and interaction parameters. Part I. Fluid Phase Equilibria, 295(1), 93-97. doi:10.1016/j.fluid.2010.04.001

Sistla, Y. S., \& Khanna, A. 2011. Validation and Prediction of the Temperature-Dependent Henry's Constant for CO2-Ionic Liquid Systems Using the Conductor-like Screening Model for Realistic Solvation (COSMO-RS). Journal of Chemical \& Engineering Data, 56(11), 4045-4060. doi:10.1021/je200486c

Skjoldjorgensen, S., Kolbe, B., Gmehling, J., \& Rasmussen, P. 1979. Vapor-Liquid Equilibria by UNIFAC Group Contribution. Revision and Extension. Industrial \& Engineering Chemistry Process Design \& Development, 18(4), 2352-2355.

Song, Z., Zhang, C., Qi, Z., Zhou, T., \& Sundmacher, K. 2018. Computer-aided design of ionic liquids as solvents for extractive desulfurization. AIChE Journal, 64, 1013-1025. doi:10.1002/aic.15994

Song, Z., Zhou, T., Qi, Z., \& Sundmacher, K. 2017. Systematic Method for Screening lonic Liquids as Extraction Solvents Exemplified by an Extractive Desulfurization Process. ACS Sustainable Chemistry \& Engineering, 5(4), 3382-3389. doi:10.1021/acssuschemeng.7b00024

Song, Z., Zhou, T., Zhang, J., Cheng, H., Chen, L., \& Qi, Z. 2015. Screening of ionic liquids for solvent-sensitive extraction -with deep desulfurization as an example. Chemical Engineering Science, 129, 69-77. doi:https://doi.org/10.1016/i.ces.2015.02.023

Sun, L., \& Smith, R. 2013. Rectisol wash process simulation and analysis. Journal of Cleaner Production, 39, 321-328. doi:10.1016/j.jclepro.2012.05.049

Tula, A. K., Befort, B., Garg, N., Camarda, K. V., \& Gani, R. 2017. Sustainable process design \& analysis of hybrid separations. Computers \& Chemical Engineering, 105, 96-104. doi:10.1016/j.compchemeng.2016.11.031

Zhang, X., Liu, Z., \& Wang, W. 2008. Screening of ionic liquids to capture $\mathrm{CO}_{2}$ by COSMO-RS and experiments. AlChE Journal, 54(10), 2717-2728. doi:10.1002/aic.11573 
Zhang, X., Zhang, X., Dong, H. D., Zhao, Z., Zhang, S., \& Huang, Y. 2012. Carbon capture with ionic liquids: overview and progress. Energ. Environ. Sci., 5, 6668-6681. doi:10.1039/c2ee21152a

Zhao, X., Yang, Q., Xu, D., Bao, Z., Zhang, Y., Su, B., . . . Xing, H. 2015. Design and screening of ionic liquids for $\mathrm{C} 2 \mathrm{H} 2 / \mathrm{C} 2 \mathrm{H} 4$ separation by COSMO-RS and experiments. AlChE Journal, 61(6), 2016-2027. doi:10.1002/aic.14782

Zhao, Y., Gani, R., Afzal, R. M., Zhang, X., \& Zhang, S. 2017. lonic liquids for absorption and separation of gases: An extensive database and a systematic screening method. AIChE Journal, 63(4), 1353-1367. doi:10.1002/aic.15618

Zhou, T., Chen, L., Ye, Y., Chen, L., Qi, Z., Freund, H., \& Sundmacher, K. 2012. An Overview of Mutual Solubility of Ionic Liquids and Water Predicted by COSMO-RS. Industrial \& Engineering Chemistry Research, 51(17), 6256-6264. doi:10.1021/ie202719z

Zhou, T., Qi, Z., \& Sundmacher, K. 2014. Model-based method for the screening of solvents for chemical reactions. Chemical Engineering Science, 115, 177-185. doi:https://doi.org/10.1016/i.ces.2013.11.020 